\title{
Divalent Nonaqueous Metal-Air Batteries
}

\author{
Yi-Ting Lu ${ }^{1,2}$, Alex R. Neale ${ }^{1}$, Chi-Chang $\mathrm{Hu}^{2}$ and Laurence J. Hardwick ${ }^{1 *}$ \\ ${ }^{1}$ Department of Chemistry, Stephenson Institute for Renewable Energy, University of Liverpool, Liverpool, United Kingtom, \\ ${ }^{2}$ Department of Chemical Engineering, National Tsing Hua University, Hsin-Chu, Taiwan
}

OPEN ACCESS

Edited by:

Jian Liu,

University of British Columbia

Okanagan, Canada

Reviewed by:

Liqiang Mai,

Wuhan University of Technology,

China

Vincenzo Baglio,

National Research Council (CNR), Italy

*Correspondence:

Laurence J. Hardwick

hardwick@liverpool.ac.uk

Specialty section:

This article was submitted to Electrochemical Energy Conversion and Storage,

a section of the journal

Frontiers in Energy Research

Received: 04 September 2020

Accepted: 20 November 2020

Published: 12 February 2021

Citation:

Lu Y-T, Neale AR, Hu C-C and Hardwick LJ (2021) Divalent Nonaqueous Metal-Air Batteries.

Front. Energy Res. 8:602918.

doi: 10.3389/fenrg.2020.602918
In the field of secondary batteries, the growing diversity of possible applications for energy storage has led to the investigation of numerous alternative systems to the state-of-the-art lithium-ion battery. Metal-air batteries are one such technology, due to promising specific energies that could reach beyond the theoretical maximum of lithium-ion. Much focus over the past decade has been on lithium and sodium-air, and, only in recent years, efforts have been stepped up in the study of divalent metal-air batteries. Within this article, the opportunities, progress, and challenges in nonaqueous rechargeable magnesium and calcium-air batteries will be examined and critically reviewed. In particular, attention will be focused on the electrolyte development for reversible metal deposition and the positive electrode chemistries (frequently referred to as the "air cathode"). Synergies between two cell chemistries will be described, along with the present impediments required to be overcome. Scientific advances in understanding fundamental cell (electro)chemistry and electrolyte development are crucial to surmount these barriers in order to edge these technologies toward practical application.

Keywords: metal-air batteries, divalent cations, magnesium batteries, calcium batteries, metal electroplating, oxygen electrochemistry

\section{INTRODUCTION}

Energy storage technologies are under extensive investigation because they could contribute towards resolving a major challenge encountered by modern society, that is, the increasing demand for energy. Batteries can be used to achieve this goal by storing energy from intermittent renewable energy sources (such as solar and wind) and releasing the energy at the point of use when required. Lithium-ion batteries are the most advanced technology, which can store and deliver energy through thousands of cycles or even more (Li et al., 2020b; Ng et al., 2020). However, though enormous progress has been made improving specific energy $\left(\mathrm{Wh} \mathrm{kg}^{-1}\right.$ ) and reducing costs of Li-ion over the past decade, the specific energy of this cell chemistry is nearing its theoretical limit. Therefore, alternative battery chemistries such as metal-air batteries are becoming attractive for their much higher theoretical specific energies than those of Li-ion, as shown in Table 1. Much attention has been focused on the Li-air cell since Abraham et al. reintroduced the concept (Abraham and Jiang, 1996), and Bruce's group demonstrated that lithium peroxide $\left(\mathrm{Li}_{2} \mathrm{O}_{2}\right)$ could be oxidized from the cathode (Ogasawara et al., 2006). Since then, $\mathrm{Li}$ and its analogs such as $\mathrm{Na}$ and $\mathrm{K}$ have been studied to make metal-air batteries (Hartmann et al., 2013; Ren and Wu, 2013; Luo et al., 2019b; Gilmore and Sundaresan, 2019; Li et al., 2020a; Ha et al., 2020; Han et al., 2020; Hu et al., 2020). Until now, many issues remain unsolved for these metal-air batteries. For example, $\mathrm{Li}, \mathrm{Na}$, and $\mathrm{K}$ anodes are plagued with poor reversibility because of their high reactivity with the electrolyte and the severe dendrite formation, which may trigger short circuits within the cell and even lead to serious fires or explosions 
TABLE 1 | Theoretical specific energies and cell voltages for various nonaqueous metal-air batteries and conventional Li-ion batteries.

\begin{tabular}{|c|c|c|}
\hline Cell chemistry & Cell voltage (V) & $\begin{array}{l}\text { Theoretical specific energy } \\
\left(\mathrm{Wh} \mathrm{kg}^{-1}\right)\end{array}$ \\
\hline Li-ion: $\mathrm{Ni}_{0.8} \mathrm{Mn}_{0.1} \mathrm{Co}_{0.1} \mathrm{O}_{2}+\mathrm{LiC}_{6} \rightarrow \mathrm{LiNi}_{0.8} \mathrm{Mn}_{0.1} \mathrm{Co}_{0.1} \mathrm{O}_{2}+\mathrm{C}_{6}$ & 3.9 & 617 \\
\hline $\mathrm{Li}-\mathrm{O}_{2}$ & $2.96\left(\mathrm{Li}_{2} \mathrm{O}_{2}\right)$ & $3,456\left(\mathrm{Li}_{2} \mathrm{O}_{2}\right)$ \\
\hline $\mathrm{Na}-\mathrm{O}_{2}$ & $\begin{array}{c}2.33\left(\mathrm{Na}_{2} \mathrm{O}_{2}\right) \\
2.27\left(\mathrm{NaO}_{2}\right)\end{array}$ & $\begin{array}{l}1,602\left(\mathrm{Na}_{2} \mathrm{O}_{2}\right) \\
1,105\left(\mathrm{NaO}_{2}\right)\end{array}$ \\
\hline $\mathrm{K}-\mathrm{O}_{2}$ & $\begin{array}{l}2.20\left(\mathrm{~K}_{2} \mathrm{O}_{2}\right) \\
2.48\left(\mathrm{KO}_{2}\right)\end{array}$ & $\begin{array}{c}1,070\left(\mathrm{~K}_{2} \mathrm{O}_{2}\right) \\
935\left(\mathrm{KO}_{2}\right)\end{array}$ \\
\hline $\mathrm{Mg}-\mathrm{O}_{2}$ & $\begin{array}{l}2.95(\mathrm{MgO}) \\
2.94\left(\mathrm{MgO}_{2}\right)\end{array}$ & $\begin{array}{c}3,921(\mathrm{MgO}) \\
2,801\left(\mathrm{MgO}_{2}\right)\end{array}$ \\
\hline $\mathrm{Ca}-\mathrm{O}_{2}$ & $\begin{array}{c}3.13(\mathrm{CaO}) \\
3.38\left(\mathrm{CaO}_{2}\right)\end{array}$ & $\begin{array}{l}2,989(\mathrm{CaO}) \\
2,515\left(\mathrm{CaO}_{2}\right)\end{array}$ \\
\hline $\mathrm{Zn}-\mathrm{O}_{2}$ & $1.65(\mathrm{ZnO})$ & 1,086 (ZnO) \\
\hline
\end{tabular}

Chemical formula of primary discharge product shown in brackets.

TABLE 2 | Theoretical capacities (gravimetric and volumetric), redox potentials under standard aqueous conditions, and abundance of various metal anodes. Abundance values are taken from reference (Haynes, 2014).

\begin{tabular}{|c|c|c|c|c|}
\hline Metal anode & $\begin{array}{l}\text { Redox potential } \\
\text { (V vs. SHE) }\end{array}$ & 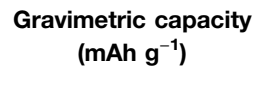 & $\begin{array}{l}\text { Volumetric capacity } \\
\qquad\left(\mathrm{mAh} \mathrm{cm}^{-3}\right)\end{array}$ & $\begin{array}{l}\text { Abundance in earth's } \\
\text { crust (ppm by } \\
\text { mass) }\end{array}$ \\
\hline $\mathrm{Li}$ & -3.04 & 3,860 & 2,062 & 20 \\
\hline $\mathrm{Na}$ & -2.71 & 1,166 & 1,129 & 23,600 \\
\hline $\mathrm{K}$ & -2.90 & 685 & 591 & 20,900 \\
\hline $\mathrm{Mg}$ & -2.37 & 2,205 & 3,832 & 23,300 \\
\hline $\mathrm{Ca}$ & -2.87 & 1,337 & 2,073 & 41,500 \\
\hline $\mathrm{Zn}$ & -0.80 & 820 & 5,851 & 70 \\
\hline
\end{tabular}

(Yu et al., 2017; Hardwick and De León, 2018; Xiao et al., 2018). Some strategies may improve the cyclability of these alkali metals; for instance, Liu and coworkers performed a cell-level analysis to provide suggestions that integrate the best material properties with optimal cell design parameters. Following these design tips, a lithium-metal cell having specific energy beyond $500 \mathrm{Wh} \mathrm{kg}^{-1}$ can be achieved with good cycling (Liu et al., 2019). Jiao's group demonstrated stable $\mathrm{Na}$ cycling with an average Coulombic efficiency of $97 \%$ over 400 cycles by adding sodium hexafluoroarsenate $\left(\mathrm{Na}\left[\mathrm{AsF}_{6}\right]\right)$ as an additive in organic carbonate-based electrolytes (Wang et al., 2019b). Xu's group fabricated a $\mathrm{SnO}_{2}$-coated porous carbon nanofiber as the host for $\mathrm{K}$ metal anodes, wherein $\mathrm{SnO}_{2}$ facilitates uniform $\mathrm{K}$ nucleation and deposition to suppress the dendritic growth of $\mathrm{K}$ (Zhao et al., 2020). Such design of a $K$ host enabled dendrite-free $K$ deposition/stripping with ultralong cycling for over $1700 \mathrm{~h}$.

More recently, divalent metal anodes $(\mathrm{Mg}, \mathrm{Ca})$ have received increased attention due to their natural abundance, low cost, high theoretical capacity, low redox potential (see Table 2), and anticipated improved safety. Note that literature about the electrochemistry of $\mathrm{Be}, \mathrm{Sr}$, and $\mathrm{Ba}$ is rarely seen (Leisegang et al., 2019); to the best of our knowledge, demonstration of metal-air cells using these metals has not so far been reported. Beyond the Group 2 elements, $\mathrm{Cu}$ has a comparably high reduction potential $\left(\mathrm{Cu}^{2+} / \mathrm{Cu}, 0.34\right.$ vs. SHE), and the resultant cell voltage is not comparable to those common anodes $\mathrm{Li}, \mathrm{Na}$, and $\mathrm{K}$ and therefore would be an impractical battery chemistry. $\mathrm{Zn}$ is mainly applied in aqueous rechargeable $\mathrm{Zn}$-air battery chemistries because of its high theoretical specific energy and safety (Lu et al., 2017; Fu et al., 2019). Conversely, research into the nonaqueous $\mathrm{Zn}$-air battery is still quite limited (Gelman et al., 2019; Chen et al., 2020). Some works have studied the $\mathrm{Zn}$ deposition in nonaqueous electrolytes (Liu et al., 2016); however, nonaqueous $\mathrm{Zn}$-ion batteries, rather than nonaqueous $\mathrm{Zn}$-air, are the primary subjects of these recent investigations (Han et al., 2016; Zhang et al., 2019). Therefore, this work focuses primarily on the electrochemistry of metallic $\mathrm{Mg}$ and $\mathrm{Ca}$ and their use in metal-air batteries. Furthermore, both $\mathrm{Mg}$ and $\mathrm{Ca}$ are thought to have lower propensity toward dendrite formation during battery cycling, possibly resulting from their lower self-diffusion barrier for adatoms during the plating process (Jäckle et al., 2018; Ponrouch et al., 2019; Biria et al., 2020). In addition, divalent metal-air batteries have superior theoretical specific energies compared to $\mathrm{Na}$-air and $\mathrm{K}$-air and can be comparable to Li-air, as summarized in Table 1 . Additionally, the natural abundance of $\mathrm{Mg}$ and $\mathrm{Ca}$ greatly outweighs that of Li (Table 2), indicating that lower costs per unit energy stored could be more readily achieved for $\mathrm{Mg}$ and $\mathrm{Ca}$ (for assumed similarly performing practical systems). Despite these advantages, realizing divalent metal-air batteries using earth-abundant anodes still remains rather challenging with respect to all aspects of the cell configuration, the anode, 


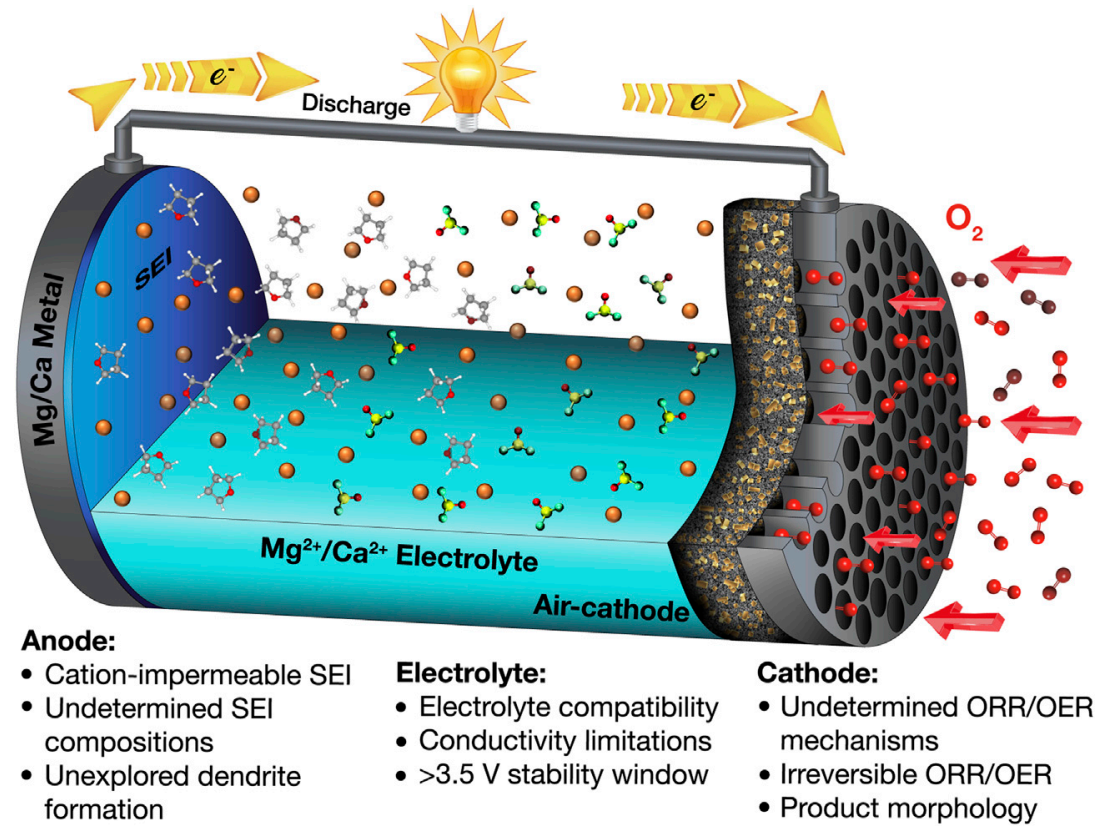

FIGURE 1 | Schematic of a discharging $\mathrm{Mg} / \mathrm{Ca}-\mathrm{O}_{2}$ cell and the challenges for nonaqueous alkaline-earth metal-air batteries.

cathode, and electrolyte, as summarized in Figure 1. By comparison to monovalent $\mathrm{Li}^{+} / \mathrm{Na}^{+}$-based electrolytes, the higher charge density of divalent $\mathrm{Mg}^{2+} / \mathrm{Ca}^{2+}$ cations yields increased interaction strength with counter-anion and surrounding environment and, thus, can inhibit solubilities, ionic transport/conductivity, and electrochemical rate capability in conventional solvent media. In terms of the anode, the solid electrolyte interphase (SEI) formed spontaneously on $\mathrm{Mg}$ and $\mathrm{Ca}$ metals is mostly impermeable to the cation in many conventional electrolyte materials, unlike the SEI on $\mathrm{Li}, \mathrm{Na}$, and $\mathrm{K}$ metal anodes, hampering the deposition/ dissolution processes (Muldoon et al., 2014; Yao et al., 2019). Regarding the air cathode, the discharge products (MO and/or $\mathrm{MO}_{2}$, where $\mathrm{M}=\mathrm{Mg}, \mathrm{Ca}$ ) generated in the oxygen reduction reaction (ORR) are usually electrochemically very stable and electrically insulating and therefore cannot be decomposed without significant applied overpotentials via the oxygen evolution reaction (OER) upon charging (Shiga et al., 2013; Reinsberg et al., 2016b; Smith et al., 2016; Li et al., 2017; Shiga et al., 2017). For the electrolyte, the most important issue is its mutual compatibility with both electrode interfaces (Hardwick and De León, 2018). Therefore, an electrolyte with a wide electrochemical window (i.e., good stability against electrochemical oxidation and reduction) is highly desirable. However, at present, an electrolyte that allows high-efficiency electrochemical reactions on both the anode (negative electrode) and cathode (positive electrode) is yet to be developed. One strategy would be using $\mathrm{Mg}^{2+} / \mathrm{Ca}^{2+}$ permeable membranes to separate the anolyte and catholyte compartments, as can be seen in other metal-air systems (Leng et al., 2015; Liang and Hayashi, 2015; Hwang et al., 2016), although extra cost, technical challenges, and rate capability of the cell need to be considered. On the other hand, issues concerning $\mathrm{CO}_{2} /$ moisture crossover will require consideration when practical cells are fabricated.

This review will critically discuss advances in the electrolyte development for the electrochemistry at both the anode and cathode for $\mathrm{Mg} / \mathrm{Ca}-\mathrm{O}_{2}$ batteries. Starting from the development of electrolytes for reversible divalent metal deposition, various established solution systems are reviewed. Although most of these electrolyte formulations are originally designed for reversible $\mathrm{Mg} / \mathrm{Ca}$ deposition or rechargeable $\mathrm{Mg} / \mathrm{Ca}$ ion batteries, some can be possible candidates to accommodate suitable oxygen electrochemistry on the cathode after modification. On the other hand, the investigations concerning the cathode electrochemistry of divalent cations that have been reported in various electrolytes are also explored. Insights into the potential ORR/OER mechanisms can be gleaned by applying various electrochemical/material characterizations. A further aspect of divalent metal-air batteries that may become critical, similar to challenges within Li-air cells, is the use of redox mediators that may address the challenge of irreversible ORR/ OER. Hence, by employing an efficient redox mediator that provides an alternate lower energy pathway toward oxidation of discharge products, a rechargeable metal-air battery could be achieved with high round-trip efficiency and avoid likely decomposition reactions commonly observed at large overpotentials. Divalent metal-air battery research is still in its infancy, and most of the recent works only target the processes at one electrode interface. Therefore, this review will discuss what has been reported previously for the anode and cathode, respectively, and aims to inspire possible future research directions for the full divalent metal-air cell (and/or battery). 


\section{ELECTROLYTE DEVELOPMENT FOR METAL ELECTRODEPOSITION}

Electrolyte development for divalent cation-based metal-air batteries creates different challenges from the analogous monovalent alkali metals, primarily attributed to the nature of divalent cations. Owing to their high charge density (i.e., chemical hardness), divalent cations suffer from significantly stronger cation-anion (ion pairing) and cation-solvent interactions, resulting in lower cation mobility and higher energy penalty for desolvation during the process of electroplating (Tchitchekova et al., 2017). Much of the electrolyte development for Mg- and Ca-based electrolytes has concerned the stable plating and stripping processes at the metal anodes. This work and the current state of the art are explored and discussed in the following sections. Furthermore, the realization of an electrolyte formulation with suitable properties for good performance at the anode, as well as at the air cathode, is likely to prove a serious challenge. Consideration is given to the applicability of these systems for use at the air cathodes, and recommendations made for systems deserve further investigations or considerable modifications before use.

\section{Magnesium Metal}

\section{Grignard Reagents for Magnesium Deposition}

Early research on $\mathrm{Mg}^{2+}$-containing electrolytes was predominantly focused on the electrodeposition of $\mathrm{Mg}$ metal. The combination of simple $\mathrm{Mg}$ salts (magnesium bromide, ethoxide, methoxide, perchlorate, and thiocyanate) and commonly used solvents (acetonitrile, aniline, benzonitrile, bromoethane, dimethylaniline, ether, formamide, o-toluidine, and pyridine) did not result in any Mg electrodeposition. By contrast, the use of organomagnesium halides (so-called Grignard reagent, $\mathrm{RMgX}, \mathrm{R}=$ alkyl or aryl group and $\mathrm{X}=$ halide like $\mathrm{Cl}$ or $\mathrm{Br}$ ) in ethereal solutions enabled the electroplating of $\mathrm{Mg}$ (Overcash and Mathers, 1933). Connor and coworkers investigated the $\mathrm{Mg}$ electrodeposition in Grignard reagents, wherein the deposit obtained from Grignard reagent ethylmagnesium bromide $(\mathrm{EtMgBr}$ in diethyl ether, $2.5 \mathrm{M}$ ) contained $71 \% \mathrm{Mg}$ (Connor et al., 1957). Although these deposits were white and metallic, they were not pure and very brittle and the reversibility of the Mg plating process was not explored in this article. On the other hand, it could be concluded that this Grignard reagent as a deposition bath is unsatisfactory because of the irreversible deposition, byproducts, and the short life of the Grignard solution. More recently, Liebenow reported the reversible deposition of $\mathrm{Mg}$ on $\mathrm{Ag}$ and $\mathrm{Au}$ substrates using EtMgBr in tetrahydrofuran (THF) (Liebenow, 1997). Conversely, at $\mathrm{Ni}$ and $\mathrm{Cu}$ substrates, great losses of electrochemically active $\mathrm{Mg}$ were observed, indicating the substrate-dependent reversibility of $\mathrm{Mg}$ plating in this class of electrolyte. Even though the reversible Mg plating was observed, the EtMgBr/ THF electrolyte had low ionic conductivity and poor anodic stability, rendering it unsuitable in full-cell applications. Some studies have studied the direct use of Grignard reagents for $\mathrm{Mg}$ deposition (Haas and Gedanken, 2008; Guo et al., 2010; Zhao et al., 2011; Cheng et al., 2013; Chang et al., 2015). However, their limited anodic stability remains a major issue, which precludes practical applications.

\section{Organomagnesium with Aluminum- or Boron-Based Lewis Acid for Magnesium Deposition}

Apart from pure Grignard-type electrolytes (RMgX in ethereal solution), other organomagnesium-based systems have also been extensively studied, and, for instance, the combination of organomagnesium $\left(\mathrm{MgR}_{2}\right.$ or $\left.\mathrm{RMgX}\right)$ as Lewis bases with aluminum- or boron-based Lewis acids (Liebenow et al., 2000; Muldoon et al., 2012; Carter et al., 2014; Zhu et al., 2014; Dongmo et al., 2020). Brenner found that the addition of boron-containing compounds (boranes, alkylboranes, and boron halides) to Grignard reagents improves the $\mathrm{Mg}$ deposition, although a small amount of B could be codeposited with $\mathrm{Mg}$ (Brenner, 1971; Brenner and Sligh, 1971). Later, Gregory and coworkers made a breakthrough and showed that the addition of aluminum halides, which are less expensive and less toxic than boron-type compounds, to the Grignard solutions resulted in high current efficiencies of deposition and gave good $\mathrm{Mg}$ deposits, with the purity higher than $99.9 \%$ (Gregory et al., 1990). In this work, the $\mathrm{RMgCl}-\mathrm{AlCl}_{3} / \mathrm{THF}$ ( $\mathrm{R}=$ methyl, ethyl, and butyl) electrolytes were prepared at various ratios of $\mathrm{RMgCl}: \mathrm{AlCl}_{3}$, and all gave high Coulombic efficiencies (over 90\%) and bright, crystalline deposits. This work also demonstrated a simple synthesis of magnesium organoborates for the first time. Based on these exciting improvements as a result of combining the Lewis acid and Lewis base, many efforts have been made to design new aluminum- and boron-based $\mathrm{Mg}$ electrolytes and a variety of well-performing systems have been invented. For example, Aurbach's group optimized the $\mathrm{PhMgCl}-\mathrm{AlCl}_{3} / \mathrm{THF}$ ( $\mathrm{Ph}=$ phenyl group) electrolyte, which exhibited $100 \%$ reversibility combined with oxidative stability of approximately $3 \mathrm{~V}$ vs. $\mathrm{Mg}$ metal for the anodic scan (Mizrahi et al., 2008). Guo and coworkers reported the $\mathrm{Mes}_{3} \mathrm{~B}-(\mathrm{PhMgCl})_{2} / \mathrm{THF}$ electrolyte $($ Mes $=3,5$-dimethylphenyl), which showed greater anodic stability up to $3.5 \mathrm{~V}$ vs. $\mathrm{Mg}$ metal (Figure 2A-i), leading to almost $100 \%$ Coulombic efficiency for $\mathrm{Mg}$ deposition (Guo et al., 2012). Also, cyclic voltammograms (CVs) of $\mathrm{Mes}_{3} \mathrm{~B}$ $(\mathrm{PhMgCl})_{2} / \mathrm{THF}$ electrolyte on various electrodes revealed that the anodic stability could reach up to $3 \mathrm{~V}$ (vs. $\mathrm{Mg}$ ) at $\mathrm{Pt}, \mathrm{Ni}$, and Al electrodes, enabling a large operation window with such current collector materials (Figure 2A-ii).

\section{Magnesium Halide-Based Electrolytes for Magnesium Deposition}

Another emerging class of $\mathrm{Mg}$ electrolytes is the magnesium halide-based electrolyte (Doe et al., 2014; Canepa et al., 2015; Ha et al., 2016; See et al., 2017; Hegemann et al., 2019). Replacing the organomagnesium, organoborate- and organoaluminate-type electrolytes with inorganic magnesium halide can be more favorable for practical $\mathrm{Mg}$ rechargeable batteries since the nucleophilic organic ligands in the former materials can be too reactive and unstable. The use of magnesium halide can be dated back to 1957. Conner and coworkers found that $2.5 \mathrm{M} \mathrm{MgBr}_{2} /$ diethyl ether as the electrolyte yielded dark and brittle $\mathrm{Mg}$ deposits, with the purity being $60-70 \%$, whereas a metallic $\mathrm{Mg}$ 

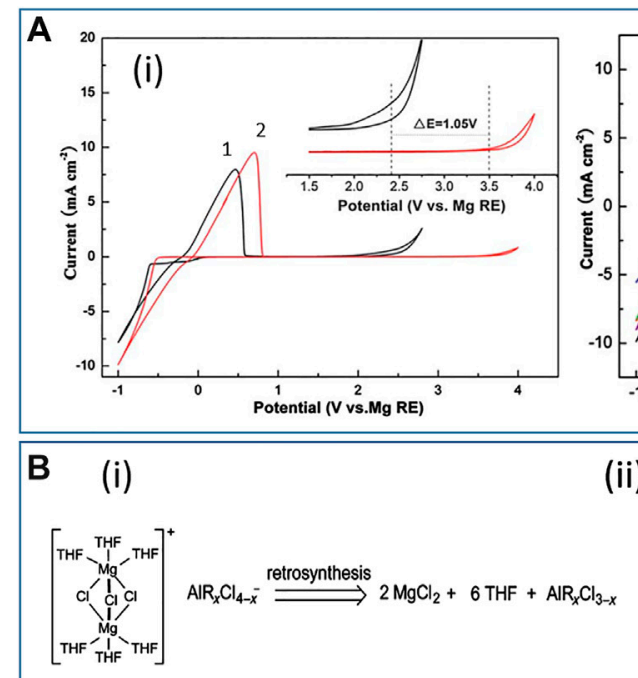

(iii)

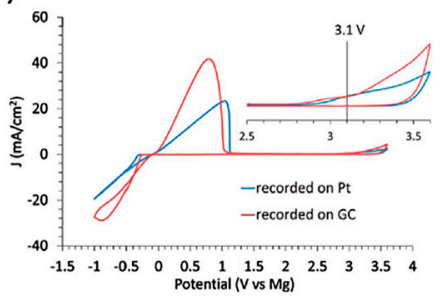

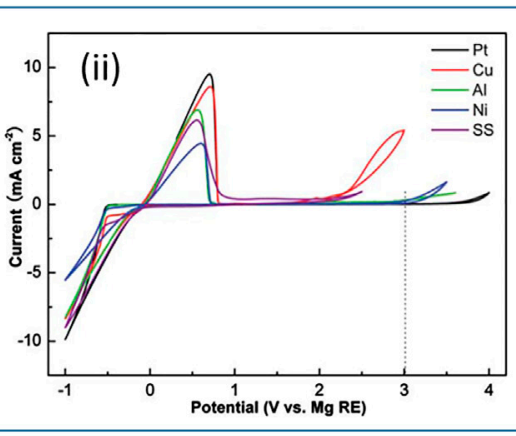
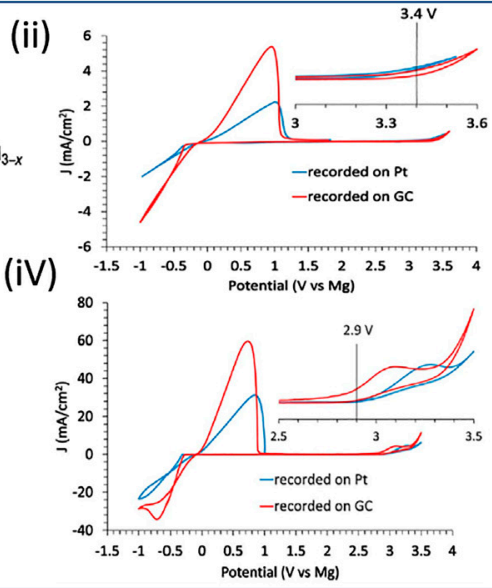
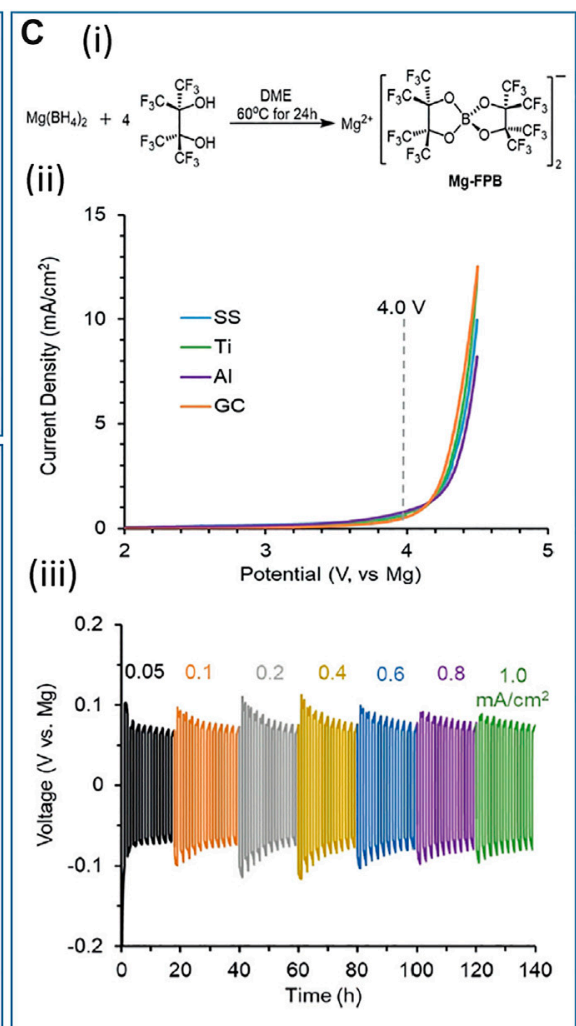

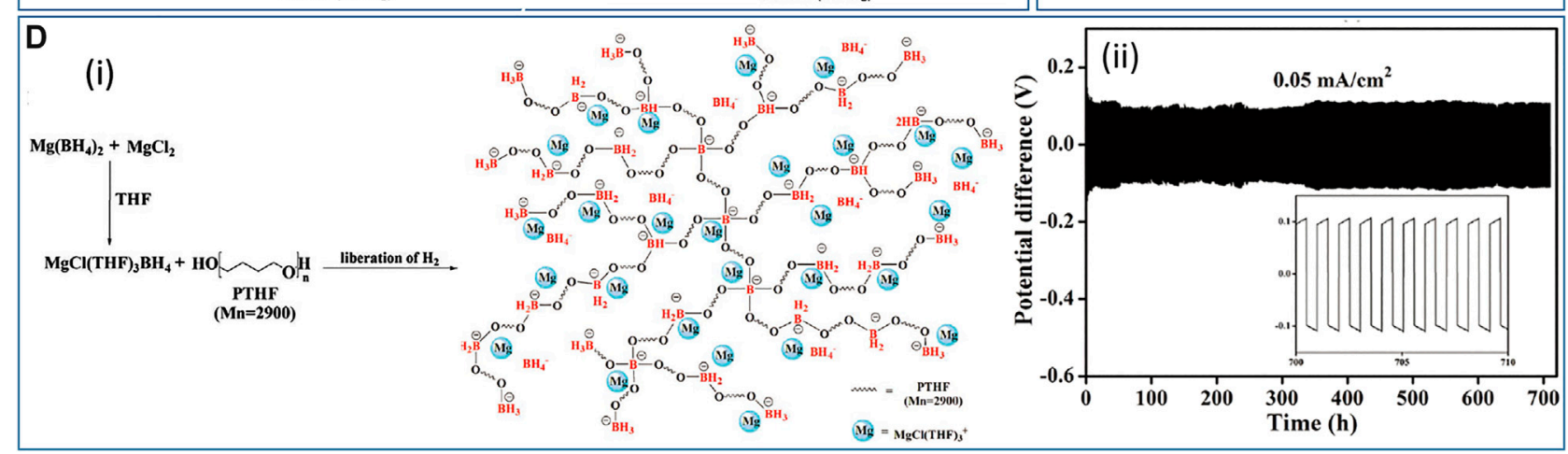

FIGURE 2 | (A-i) Cyclic voltammograms of Pt electrodes at $50 \mathrm{mV} \mathrm{s}^{-1}$ in (1) $0.4 \mathrm{M} \mathrm{Mes}_{3} \mathrm{~B}-\mathrm{PhMgCl}$ and 2) $0.5 \mathrm{M} \mathrm{Mes}{ }_{3} \mathrm{~B}-(\mathrm{PhMgCl})_{2}$. Inset is an enlargement of the 1.5-4 V region. (A-ii) Cyclic voltammograms of $\mathrm{Mes}_{3} \mathrm{~B}-(\mathrm{PhMgCl})_{2} / \mathrm{THF}$ on several working electrodes. Reproduced with permission from (Guo et al., 2012). (B-i) Retrosynthesis of electroactive $\left[\left(\mu-\mathrm{Cl}_{3} \mathrm{Mg}_{2}(\mathrm{THF})_{6}\right]^{+}\right.$species. Cyclic voltammograms of (B-ii) $\mathrm{MgCl}_{2}-\mathrm{AlCl}_{3} / \mathrm{THF},(\mathrm{B}-\mathrm{iii}) \mathrm{MgCl}_{2}-\mathrm{AlPh} / \mathrm{THF}$, and $(\mathrm{B}-\mathrm{iV}) \mathrm{MgCl}{ }_{2}-\mathrm{AlEtCl} 2 / \mathrm{THF}$ at $50 \mathrm{mV} \mathrm{s}^{-1}$ on GC and Pt. All insets show the enlargement of the oxidation region. Reproduced with permission from (Liu et al., 2014). (C-i) Synthesis of Mg-FPB.

(C-ii) Linear sweep voltammograms of $\mathrm{Mg}-\mathrm{FPB}$ at $50 \mathrm{mV} \mathrm{s}^{-1}$ on different working electrodes. (C-iii) Mg plating/stripping at current densities from 0.05 to $1 \mathrm{~mA} \mathrm{~cm}^{-2}$ in Mg/0.5 M Mg-FPB (in diglyme)/Mg symmetric cell. Reproduced with permission from (Luo et al., 2019a). (D-i) Synthetic route of PTB-GPE based on the reaction of Mg $\left[\mathrm{BH}_{4}\right]_{2}$ with $\mathrm{MgCl}_{2}$ and PTHF. (D-ii) Mg plating/stripping at $0.05 \mathrm{~mA} \mathrm{~cm}{ }^{-2}$ over $700 \mathrm{~h}$ in Mg/PTB@GF-GPE/Mg symmetric cell. Reproduced with permission from (Du et al., 2019).

deposit with a purity of $90 \%$ was observed when a small amount of $\mathrm{Li}\left[\mathrm{BH}_{4}\right]$ was added to the $\mathrm{MgBr}_{2}$ /ether electrolyte (Connor et al., 1957). Another $\mathrm{Mg}$ electrolyte of $\mathrm{MgBr}_{2} /$ ether with the addition of $\mathrm{Li}\left[\mathrm{AlH}_{4}\right]$ also showed enhanced $\mathrm{Mg}$ deposition. In this solution, the $\mathrm{Mg}$ deposit coexisted with $\mathrm{Al}$ as an alloy, with $\mathrm{Al}$ making up 1-10\% of the deposited layer. On the other hand, early attempts to apply $\mathrm{MgCl}_{2}$ as the source of $\mathrm{Mg}$ were studied by Aurbach's group and the first use of $\mathrm{MgCl}_{2}-\mathrm{AlCl}_{3} / \mathrm{THF}$ electrolyte was proposed (Viestfrid et al., 2005). In this study, the resulting
CV exhibited a Coulombic efficiency of $34 \%$ and a large cycling overpotential over $1 \mathrm{~V}$. The same group claimed in a later work that enhancing the electrochemical performance of $\mathrm{Mg}$ deposition and dissolution could be achieved by an electrochemical conditioning process consisting of a repeated cyclic voltammetry treatment (Shterenberg et al., 2014). However, such a conditioning process is not reported in many other publications. The explanation is probably related to contaminants (e.g., water, oxygen, and reactive organic 
molecules) that affect the electrochemistry, giving rise to poor $\mathrm{Mg}$ deposition behaviors (He et al., 2017). On the other hand, a dimer species $\left[(\mu-\mathrm{Cl})_{3} \mathrm{Mg}_{2}(\mathrm{THF})_{6}\right]^{+}$has been identified as the active species in electrochemically active electrolytes derived from organomagnesium precursors with Lewis acids in THF (Pour et al., 2011; Guo et al., 2012). In 2014, based on a retrosynthesis rationale (Figure 2B-i), Liu's group designed a simple synthesis that produces the electrochemically active dimer $\left[(\mu-\mathrm{Cl})_{3} \mathrm{Mg}_{2}(\mathrm{THF})_{6}\right]^{+}$in THF as electrolytes (Liu et al., 2014). In this work, $\mathrm{MgCl}_{2}$ was used as the $\mathrm{Mg}$ source in combination with various aluminum-based Lewis acids $\left(\mathrm{AlCl}_{3}, \mathrm{AlPh}_{3}\right.$, $\mathrm{AlEtCl}_{2}$ ), and these three electrolytes revealed Coulombic efficiencies above $90 \%$. The $\mathrm{MgCl}_{2}-\mathrm{AlCl}_{3}$ electrolyte showed improved oxidation stability $(3.4 \mathrm{~V}$ vs. $\mathrm{Mg}$, Figure 2B-ii) compared to $\mathrm{MgCl}_{2}-\mathrm{AlPh}_{3}\left(3.1 \mathrm{~V}\right.$, Figure 2B-iii) and $\mathrm{MgCl}_{2^{-}}$ $\mathrm{AlEtCl}_{2}\left(2.9 \mathrm{~V}\right.$, Figure 2B-iV). Nevertheless, $\mathrm{MgCl}_{2}-\mathrm{AlCl}_{3}$ had a low conductivity $\left(0.26 \mathrm{mS} \mathrm{cm}^{-1}\right)$ and poor solubility $(0.04 \mathrm{M})$, whereas $\mathrm{MgCl}_{2}-\mathrm{AlPh}_{3}$ and $\mathrm{MgCl}_{2}-\mathrm{AlEtCl}_{2}$ displayed better conductivities (2.96 and $6.99 \mathrm{mS} \mathrm{cm}^{-1}$, respectively) and solubilities ( 0.43 and $0.67 \mathrm{M}$, respectively). Although each of the electrolyte formulations had some disadvantages, it is suggested that properties of the $\mathrm{MgCl}_{2}-\mathrm{AlR}_{\mathrm{x}} \mathrm{Cl}_{3-\mathrm{x}}$ electrolytes, including anodic stability, conductivity, and solubility, can be modulated by the Lewis acid components.

\section{Ionic Liquids for Magnesium Deposition}

$\mathrm{Mg}$ deposition in ionic liquids (ILs) has also been under intense investigation due to their negligible vapor pressure, nonflammability, moderate ionic conductivity, good thermal stability, and electrochemical stability (Abdallah et al., 2012). For example, Morita's group reported an optimized cation structure of imidazolium-based ILs as "ionic solvents" to accommodate the Grignard reagent $\mathrm{MeMgBr} / \mathrm{THF}$ complex (Kakibe et al., 2010). Introducing a methyl substituent group at the 2-position of the imidazolium ring cation can suppress the reaction of imidazolium cation with $\mathrm{MeMgBr}$, stabilizing the electrolyte formulation. The authors demonstrated that utilizing an asymmetric structure of imidazolium cation, thereby lowering viscosity and increasing ionic conductivity, leads to the improved reversibility of $\mathrm{Mg}$ deposition. The optimal Coulombic efficiency in this work was $71 \%$, and the electrochemical window had a range between -1 and $3.7 \mathrm{~V}$ (vs. $\mathrm{Mg}$ ). Later, the same group studied binary IL electrolytes $[\mathrm{DEME}][\mathrm{TFSI}]_{\mathrm{n}}[\mathrm{FSI}]_{1-\mathrm{n}}(\mathrm{DEME}=$ $\mathrm{N}, \mathrm{N}$-diethyl-N-methyl-N-(2-methoxyethyl)ammonium, TFSI = bis $\{$ (trifluoromethyl)sulfonyl $\}$ imide, FSI = bis(fluorosulfonyl) imide) containing $\mathrm{MeMgBr} / \mathrm{THF}$ (Kakibe et al., 2012). The authors described the use of binary IL with mixed anions inspired by the good rechargeability and electrochemical properties demonstrated in lithium-ion battery electrolytes. CVs of $\mathrm{Mg}$ electrodeposition exhibited that [DEME][TFSI $]_{0.5}$ $[\mathrm{FSI}]_{0.5}$ has the highest deposition charge and lowest overpotentials of plating/stripping compared to other binary IL formulations, which could be the preferable ionic structure of this IL composition for $\mathrm{Mg}$ deposition to proceed. A Coulombic efficiency above $90 \%$ could be achieved over 100 cycles in the galvanostatic Mg deposition/dissolution test. These works revealed that ILs have primarily been used to dissolve Mg salts as solvents, suggesting that ILs can potentially be applied to various electrolyte systems aside from Grignard reagents; for example, IL-based electrolytes containing $\mathrm{Mg}\left[\mathrm{BH}_{4}\right]_{2}, \mathrm{Mg}[\mathrm{TFSI}]_{2}$, or $\mathrm{Mg}\left[\mathrm{ClO}_{4}\right]_{2}$ salts can be seen in the literature (Narayanan et al., 2009; Watkins et al., 2016; Lee et al., 2018; Gao et al., 2019; Ma et al., 2019). Since the characteristic properties of ILs can be modified by controlling the ion structures, ILs with improved (electro)chemical properties could potentially be designed to facilitate highperformance $\mathrm{Mg}$ deposition/dissolution.

\section{Solid-State Electrolytes for Magnesium Deposition}

Besides liquid electrolytes, the use of solid-state electrolytes for $\mathrm{Mg}$ deposition has also been explored (Kumar and Munichandraiah, 1999; Pandey and Hashmi, 2009; Sarangika et al., 2017; Deivanayagam et al., 2019; Fan et al., 2020). Despite their low ionic conductivities, solid-state electrolytes are in general safer because they are leak-proof and nonflammable (Jaschin et al., 2020). For example, Higashi and coworkers invented an inorganic solid-state electrolyte of $\mathrm{Mg}\left[\mathrm{BH}_{4}\right]\left[\mathrm{NH}_{2}\right]$ (Higashi et al., 2014). $\mathrm{Mg}\left[\mathrm{BH}_{4}\right]\left[\mathrm{NH}_{2}\right]$ was derived from $\mathrm{Mg}\left[\mathrm{BH}_{4}\right]_{2}$ and possessed much higher ionic conductivity $\left(10^{-3}\right.$ and $10^{-6} \mathrm{mS} \mathrm{cm}^{-1}$ for $\mathrm{Mg}\left[\mathrm{BH}_{4}\right]\left[\mathrm{NH}_{2}\right]$ and $\mathrm{Mg}\left[\mathrm{BH}_{4}\right]_{2}$, respectively, at $150^{\circ} \mathrm{C}$ ). Although the Coulombic efficiency is not high (ca. 50\%), negligible onset potential difference between plating and stripping processes indicates the reversibility could be acceptable at $150{ }^{\circ} \mathrm{C}$, and the anodic stability is shown to be ca. $3 \mathrm{~V}$ (vs. $\mathrm{Mg}$ ). In addition to acting as the electrolyte, the authors commented that such a thin solid electrolyte can be utilized as a coating layer for $\mathrm{Mg}$ metal, which separates the $\mathrm{Mg}$ metal from the conventional liquid electrolytes, therefore allowing for versatile applications. Polymer electrolytes, which may combine the high conductivity of liquid electrolytes and the above-mentioned advantages of solid electrolytes, can also be utilized as solid-state electrolytes for Mg plating (Kim et al., 2013). In 2003, Aurbach's group first reported a polymer electrolyte $\mathrm{Mg}$ $\left[\mathrm{AlCl}_{2} \mathrm{EtBu}\right]_{2} /$ tetraglyme/PVdF tested in a rechargeable $\mathrm{Mg}$-ion cell that had good cyclability in a wide temperature range between 0 and $80^{\circ} \mathrm{C}$ (Chusid et al., 2003). This polymer electrolyte had good anodic stability up to $2.5 \mathrm{~V}$ (vs. $\mathrm{Mg}$ ) and ionic conductivity of $3.7 \mathrm{mS} \mathrm{cm}^{-1}$ at $25^{\circ} \mathrm{C}$. In 2015 , Shao and coworkers fabricated a nanocomposite electrolyte based on polyethylene oxide (PEO), $\mathrm{MgO}$, and $\mathrm{Mg}\left[\mathrm{BH}_{4}\right]_{2}$ with a Coulombic efficiency of $98 \%$ at $100{ }^{\circ} \mathrm{C}$, and the voltage gap between the onset potentials for stripping and plating was only $0.2 \mathrm{~V}$ (Shao et al., 2015). The PEO has electron lone pairs on its ether-type oxygen, which exhibits strong coordinating capability. Therefore, even though complete dissociation is proven unlikely, the dissociation of $\mathrm{Mg}\left[\mathrm{BH}_{4}\right]_{2}$ in PEO could be enhanced, leading to better deposition performance.

\section{Other Design Concepts of Electrolytes for Magnesium Deposition}

As the development of electrolytes proceeds, some state-of-theart electrolytes have been reported with new design concepts. In 2019, Liu's group developed a chloride-free, electrochemically active, and anodically stable magnesium fluorinated pinacolatoborate electrolyte, $\mathrm{Mg}\left[\mathrm{B}\left(\mathrm{O}_{2} \mathrm{C}_{2}\left(\mathrm{CF}_{3}\right)_{4}\right)_{2}\right]_{2}$ (abbreviated as $\mathrm{Mg}-\mathrm{FPB}$, Figure $\mathbf{2 C - i )}$ in diglyme, in order to replace 
chloride-based electrolytes that are possibly corrosive at positive potentials (Luo et al., 2019a). The strong chelating effect of bidentate alkyloxide ligands can stabilize the B center and, therefore, the resultant anion can withstand larger positive polarization. The $\mathrm{Mg}-\mathrm{FPB} /$ diglyme electrolyte delivered a Coulombic efficiency of $95 \%$ for the $\mathrm{Mg}$ plating/stripping processes, and the anodic stability was up to $4 \mathrm{~V}$ (vs. $\mathrm{Mg}$ ) on stainless steel, $\mathrm{Ti}, \mathrm{Al}$, and glassy carbon (GC) electrodes (Figure 2C-ii). The weakly coordinating $\mathrm{B}\left[\mathrm{O}_{2} \mathrm{C}_{2}\left(\mathrm{CF}_{3}\right)_{4}\right]_{2}$ anion plays a pivotal role in providing a wide potential window, which is potentially suitable to high-voltage cathode materials. In addition, the weak cation-anion interaction gives higher solubility and good ionic conductivity in the electrolyte $\left(0.5 \mathrm{M}\right.$ and $3.95 \mathrm{mS} \mathrm{cm}^{-1}$ ). A symmetric $\mathrm{Mg} / 0.5 \mathrm{M} \mathrm{Mg-FPB} \mathrm{(in}$ diglyme $/ \mathrm{Mg}$ cell was assembled to evaluate the long-term electrochemical performance at various current densities (Figure 2C-iii), and the polarization under galvanostatic control was below $100 \mathrm{mV}$ for all current densities measured. More surprisingly, nuclear magnetic resonance (NMR) results suggested negligible hydrolysis of the electrolyte two days after the addition of water $(10,000 \mathrm{ppm})$. This observation implies that $\mathrm{Mg}-\mathrm{FPB} /$ diglyme is a promising choice for practical metal-air batteries where moisture impurities from the external gas supply are possible and likely.

Another work presented by Wang and coworkers demonstrated reversible $\mathrm{Mg}$ deposition in the dual-salt electrolyte $0.4 \mathrm{M} \mathrm{Mg}[\mathrm{TFSI}]_{2} / 0.1 \mathrm{M} \mathrm{Mg}\left[\mathrm{BH}_{4}\right]_{2} /$ diglyme (Wang et al., 2019a). The addition of a relatively small amount of $\mathrm{Mg}$ $\left[\mathrm{BH}_{4}\right]_{2}$ prevents the decomposition of [TFSI $]^{-}$, rendering the electrodeposition reversible. This article proposed that although $\mathrm{Mg}$ can be deposited from the conventional electrolyte without $\mathrm{Mg}\left[\mathrm{BH}_{4}\right]_{2}$, the deposited $\mathrm{Mg}$ reacts rapidly with the $[\mathrm{TFSI}]^{-}$anion in the $\left[\mathrm{Mg}[\mathrm{TFSI}](\text { diglyme })_{2}\right]^{+}$cluster present in the bulk electrolyte. In contrast, introducing $\mathrm{Mg}$ $\left[\mathrm{BH}_{4}\right]_{2}$ neutralizes the solvation shell of the $[\mathrm{Mg}$ $\left.[\mathrm{TFSI}](\text { diglyme })_{2}\right]^{+}$cluster, turning it into $\left[\mathrm{Mg}\left[\mathrm{BH}_{4}\right]\right.$ [TFSI](diglyme)], since $\left[\mathrm{BH}_{4}\right]^{-}$is a rather strong coordinating ligand. This neutralized cation cluster somehow inhibits the decomposition of [TFSI $^{-}$in the solvation shell. With this advantageous dual-salt formulation, a Coulombic efficiency of 99\% was achieved, and X-ray photoelectron spectroscopy (XPS) results displayed that most of the $\mathrm{Mg}$ deposits were $\mathrm{Mg}$ metal instead of $\mathrm{Mg}^{2+}$. Besides, no B, N, F, or S signals were found on the deposited $\mathrm{Mg}$. As for solid-state electrolytes, Du and coworkers developed a crosslinked polytetrahydrofuran-boratebased gel polymer electrolyte (Figure 2D-i) with the addition of $\mathrm{MgCl}_{2}$ inside a glass fiber membrane (PTB@GF-GPE), which allowed not only reversible $\mathrm{Mg}$ plating/stripping for $700 \mathrm{~h}$ at $0.05 \mathrm{~mA} \mathrm{~cm}^{-2}$ (Figure 2D-ii), but also a wide operation temperature range between -20 and $60{ }^{\circ} \mathrm{C}$ (Du et al., 2019). Differing from other works using $\mathrm{Mg}\left[\mathrm{BH}_{4}\right]_{2} / \mathrm{THF}$ liquid electrolyte, this work attempted to design a crosslinked polymer matrix, which enables facile $\mathrm{Mg}^{2+}$ transfer, to act as a gel polymer electrolyte with improved mechanical strength and thermal stability. To achieve this goal, polytetrahydrofuran (PTHF, average molecular weight $=2,900)$ and $\mathrm{Mg}\left[\mathrm{BH}_{4}\right]_{2}$ were dissolved in THF, and a reaction between $\left[\mathrm{BH}_{4}\right]^{-}$and the hydroxyl functional groups occurred in situ on a glass fiber membrane. After the crosslinking, the anion $\left[\mathrm{BH}_{4}\right]^{-}$reacted with the PTHF polymer, generating a PTHF-borate-based gel polymer electrolyte, PTB@GF-GPE. In such structure, the anion can be incorporated into the large, immobilized polymer matrix, resulting in a high transference number of 0.73 for $\mathrm{Mg}^{2+}$ cations at the room temperature.

\section{Summary of Electrolyte Development and Outlook for Magnesium Deposition}

For rechargeable $\mathrm{Mg}$-air batteries, irreversible $\mathrm{Mg}$ plating/ stripping should be overcome first. Also, the oxidative stability of electrolytes should be high enough to be compatible with the electrochemistry of oxygen and reaction intermediates generated at the positive electrode interface. To be more specific, the electrolyte must, at least, keep stable at ca. $3 \mathrm{~V}$ (vs. Mg), considering the theoretical cell voltage of $\mathrm{Mg}-\mathrm{O}_{2}$ cell (refer to Table 1). In practicality, significant overpotentials for the recharging (oxidative decomposition) of any $\mathrm{MgO} / \mathrm{MgO}_{2}$ discharge products are likely. Consequently, anodic stability limits exceeding $c a .3 .5 \mathrm{~V}$ would likely be required. A variety of electrolyte systems have been investigated to achieve these goals, and progress has been summarized in Figure 3, along with comparative information for Ca-based systems discussed in the next subsection. Many sorts of Grignard reagents are sufficiently electroactive; nevertheless, their instability caused by the nucleophilic nature restricts their practical application. Lewis acids as additives could be an effective solution to the instability of Grignard reagents, as demonstrated by the aluminum- or boron-based Lewis acids. Meanwhile, a retrosynthesis strategy suggests that it is possible to use $\mathrm{Mg}$ halides as $\mathrm{Mg}$ sources for the $\mathrm{Mg}$ electrodeposition with high reversibility. Substituting $\mathrm{Mg}$ halides for any possible organic species as the $\mathrm{Mg}$ source can be used to enhance the electrochemical stability of electrolyte. However, the relatively low conductivity and salt solubility of such systems still need to be resolved. Another concern is that the electrochemical oxidation stability of electrolytes containing chloride substantially depends on the current collector used (Liu et al., 2014). The incompatibility of chloride-containing electrolytes with certain current collectors (e.g., Al or stainless steel) could easily cause electrolyte degradation during cycling.

The appeal of ILs as candidate electrolyte solvents is related to the excellent safety, negligible volatility, and good ionic conductivity of many different cation and anion combinations. As the cation and anion structures both contribute to the properties of ILs, modification of ILs for better properties tailored toward electrochemical deposition can be achieved through structure optimization. Given that metal-air batteries require an electrolyte compatible with the cathode and the ORR intermediates and products (i.e., superoxide and peroxide), ILs could be a potential candidate owing to their typically good (electro)chemical stability. More investigations on IL blends (with another ionic liquid or another organic solvent) are also recommended, considering many synergistic effects on electrochemistry in such blends have been reported in the literature (Lair et al., 2010; Giridhar et al., 2012; Grande et al., 


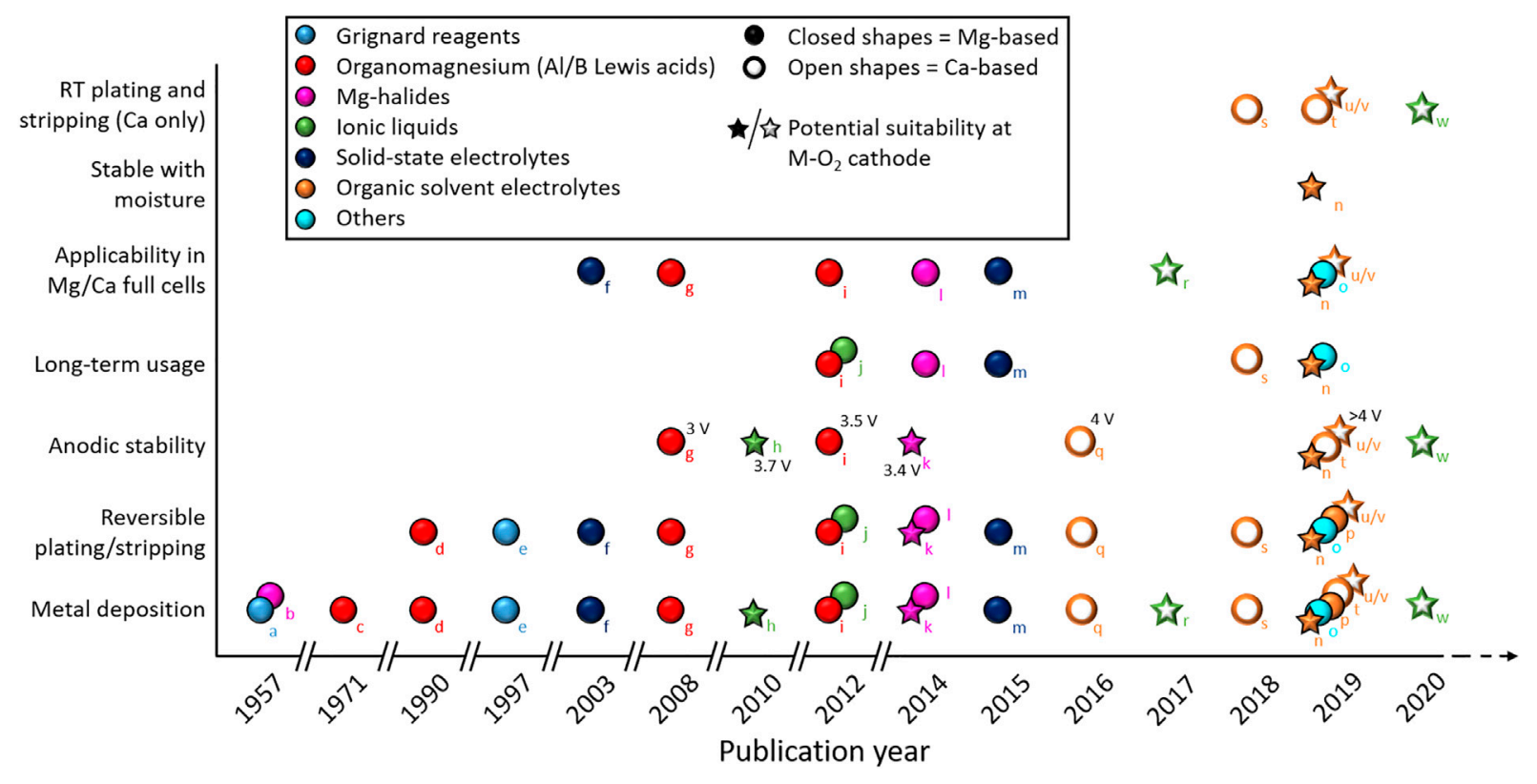

FIGURE 3 | Summary figure of the progress of electrolyte development, highlighting various technical achievements, for Mg (closed shapes) and Ca (open shapes) plating/stripping cycling. Electrolytes are grouped by color to show the type of materials used and the star symbols highlight particular formulations that possess properties making them promising candidates for future investigations in $\mathrm{Mg} / \mathrm{Ca}-\mathrm{O}_{2}$ batteries. Labels a-w refer to literature cited in this section and are summarized in the supporting information ( $R T$ = room temperature).

2015; Neale et al., 2017). Solid-state electrolytes are also promising electrolyte systems for metal-air batteries, taking into account their mechanical strength, leak-free feature, and nonflammability. Gel polymer electrolytes are, in particular, a famous subject to be applied in Li-air cells (Yi et al., 2015). In recent decades, an emerging class of materials called organic ionic plastic crystals (OIPCs) have been studied as solid-state electrolytes. Such plastic crystals have a definite threedimensional lattice, but some fraction can be allowed to flow under stress due to the structural disorder stemming from rotational or reorientational motions of cations and/or anions (Pringle et al., 2010; Goossens et al., 2019). Some research about OIPCs applied in Li-battery applications can be found in the literature (MacFarlane et al., 1999; Zhou and Matsumoto, 2007; Jin et al., 2014). Nonetheless, the direct use of OIPCs for efficient $\mathrm{Mg}$ stripping/plating is yet to be reported to the best of our knowledge. On the other hand, it will also be valuable to continue working on electrolytes with innovative design concepts. As discussed, $\mathrm{Mg}-\mathrm{FPB} /$ diglyme shows good anodic stability and good reversibility, while the addition of $\mathrm{Mg}\left[\mathrm{BH}_{4}\right]_{2}$ can allow reversible $\mathrm{Mg}$ deposition in conventional electrolyte $\mathrm{Mg}[\mathrm{TFSI}]_{2} /$ diglyme that is unstable with $\mathrm{Mg}$ metal. Also, glyme-based electrolytes have been used widely in metal-air battery applications (Aldous and Hardwick, 2016; Yu et al., 2017; Carbone et al., 2018). Considering new approaches that enable the utilization of conventional electrolytes in $\mathrm{Mg}$ deposition, some traditional electrolytes could be worthy of a reevaluation, suggesting another possible research direction.

\section{Calcium Metal}

Staniewicz reported the earliest work on Ca-metal based cells, based on a thionyl-chloride $\left(\mathrm{SOCl}_{2}\right)$ system, utilizing a tetrachloroaluminate calcium salt $\left(\mathrm{Ca}\left[\mathrm{AlCl}_{4}\right]_{2}\right)$ in $\mathrm{SOCl}_{2}$ (Staniewicz, 1980). The Ca-metal surface suffered serious corrosion under discharge and storage, generating $\mathrm{CaCl}_{2}$ as a primary product and electroplating of $\mathrm{Ca}$ (onto a Ni substrate) could not be observed in this electrolyte system. Later, the important work of Aurbach et al. demonstrated the practical impossibility of achieving Ca electroplating in a series of more conventional nonaqueous electrolyte systems (Aurbach et al., 1991). Therein, reducing currents were ascribed to the reductive decomposition of the electrolyte solvent or salt and no evidence for electroplated $\mathrm{Ca}$ was observed. The authors attributed this to surface passivation and the lack of $\mathrm{Ca}^{2+}$ ion mobility in the surface films formed.

\section{Organic Solvent Electrolytes for Calcium Deposition and the Importance of Borate-Based Salts}

Ponrouch and coworkers demonstrated the first evidence for the electroplating of Ca metal four years ago (Ponrouch et al., 2016). By employing raised temperatures $\left(75-100{ }^{\circ} \mathrm{C}\right)$, plating/stripping redox was achieved on stainless steel electrodes using a $\mathrm{Ca}\left[\mathrm{BF}_{4}\right]_{2}$ salt in a 1:1 mixture of propylene carbonate (PC) and ethylene carbonate (EC, see Figure 4A). The authors demonstrated some evidence that $\mathrm{Ca}\left[\mathrm{ClO}_{4}\right]_{2}$ salts also support plating and stripping but with poorer reversibility, whereas $\mathrm{Ca}[\mathrm{TFSI}]_{2}$ electrolytes showed no evidence of stripping electrochemistry. Deposited 

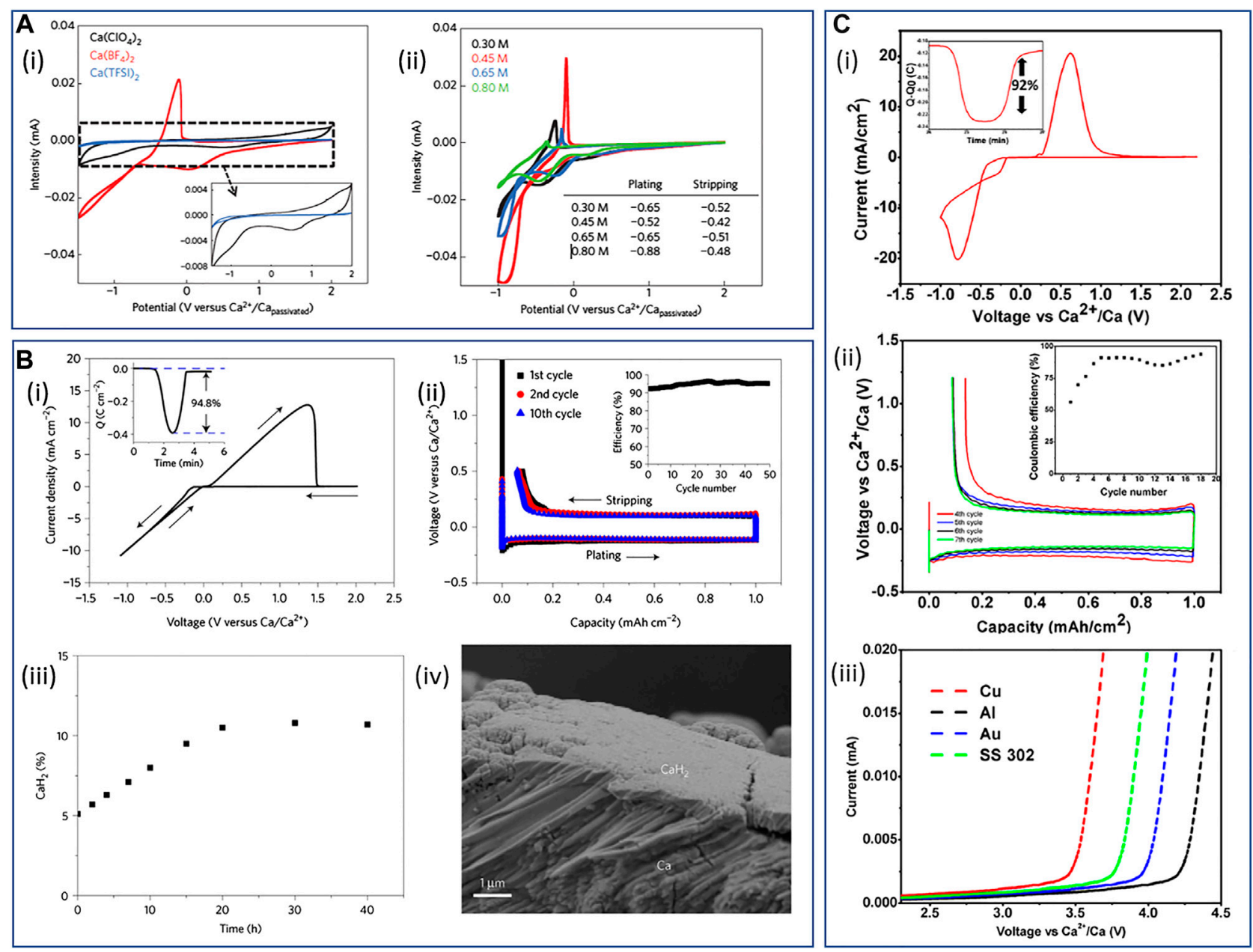

FIGURE 4 | (A) Cyclic voltammograms of EC:PC-based electrolytes $\left(0.5 \mathrm{mV} \mathrm{s}^{-1}\right.$ scan rate) at $100^{\circ} \mathrm{C}$ with (i) a $0.3 \mathrm{M}$ concentration of different Ca ${ }^{2+}$ salts and (ii) a range of $\mathrm{Ca}\left[\mathrm{BF}_{4}\right]_{2}$ concentrations from 0.3 to $0.8 \mathrm{M}$. Reproduced with permission from (Ponrouch et al., 2016). (B) Calcium plating/stripping in $1.5 \mathrm{M} \mathrm{Ca}[\mathrm{BH} 4]_{2} / \mathrm{THF}$; (i) Cyclic voltammogram of calcium plating/stripping. The working, reference, and counter electrode are $\mathrm{Au}, \mathrm{Ca}$, and Pt, respectively. Scan rate $25 \mathrm{mV} \mathrm{s}{ }^{-1}$. Inset shows charge passed on plating/stripping from the CV. (ii) Galvanostatic calcium plating/stripping at a rate of $1 \mathrm{~mA} \mathrm{~cm}^{-2}$ (iR-corrected). The working, reference, and counter electrode are $\mathrm{Au}, \mathrm{Ca}$, and $\mathrm{Ca}$, respectively. (iii) Accumulation of $\mathrm{CaH}_{2}$ at open circuit after depositing $1 \mathrm{mAh} \mathrm{cm}^{-2}$ of calcium on the electrode, expressed as a mole percentage of the charge passed and (iv) the cross-sectional image of the electrode after $20 \mathrm{~h}$ rest at open circuit. Reproduced with permission from (Wang et al., 2018a). (C) Electrochemical measurements in $\mathrm{Ca}\left[\mathrm{B}(\mathrm{Ohfip})_{4}\right]_{2} / \mathrm{DME}$ electrolyte: (i) fourth $\mathrm{CV}$ cycle on an Au substrate with calcium as the reference and counter electrode (scan rate of $25 \mathrm{mV} \mathrm{s}^{-1}$ ); (ii) galvanostatic plating/stripping of calcium on an Au electrode with Ca counter- and reference electrodes at $0.2 \mathrm{~mA} \mathrm{~cm}^{-2}$ to a capacity of 1 $\mathrm{mAh} \mathrm{cm}$; (iii) linear sweep voltammograms recorded on various substrates at a scan rate of $0.05 \mathrm{mV} \mathrm{s}^{-1}$ with Ca as both the reference and counterelectrodes. Reproduced with permission from (Shyamsunder et al., 2019). Copyright 2019 American Chemical Society.

layers were shown to contain primarily phases of $\mathrm{Ca}$ and $\mathrm{CaF}_{2}$, where the fraction of the latter decreased on continued cycling, attributed to initial SEI formation (of $\mathrm{CaF}_{2}$ rich phases) in early stages of plating. Through the optimization of $\mathrm{Ca}\left[\mathrm{BF}_{4}\right]_{2}$ electrolyte conductivity, the authors were even able to demonstrate some stable electroplating/stripping cycling within symmetrical $\mathrm{Ca} / \mathrm{Ca}$ cells at $100^{\circ} \mathrm{C}$. More recently, Biria and coworkers reported on the room temperature $\mathrm{Ca}$ plating/ stripping in $\mathrm{Ca}\left[\mathrm{BF}_{4}\right]_{2}$ in $\mathrm{PC} / \mathrm{EC}$ electrolytes by utilizing $\mathrm{Cu}$ as an inert substrate (Biria et al., 2019). Therein, the process appears to be of good Coulombic efficiency (>96\%) but requires large overpotentials to support plating and stripping $\left(>1 \mathrm{~V} \mathrm{vs.} \mathrm{Ca}^{2+} / \mathrm{Ca}\right.$ at $0.55 \mathrm{~mA} \mathrm{~cm}^{-2}$ ). The resulting surface films contained no observable $\mathrm{CaF}_{2}$ phase (by X-ray diffraction), which was attributed to reduced electrolyte reactivity at lower temperatures relative to the earlier work. In the absence of additional crystalline phases, components of the carbonate solvents and entrapped $\left[\mathrm{BF}_{4}\right]^{-}$, observed by FTIR spectroscopy, composed the $\mathrm{Ca}^{2+}$ conducting layer.

The first demonstration of reversible plating and stripping of $\mathrm{Ca}$ at room temperature utilized the formulation of a $1.5 \mathrm{M} \mathrm{Ca}$ $\left[\mathrm{BH}_{4}\right]_{2} / \mathrm{THF}$ electrolyte (Wang et al., 2018a). Following an 
electrochemical reducing cleaning step, the borohydride electrolyte facilitated minimal overpotentials $(0.1 \mathrm{~V}$ at $1 \mathrm{~mA} \mathrm{~cm}^{-2}$ ) and resulted in Coulombic efficiencies of 93-95\% of Ca plating/stripping at a gold substrate (Figures 4 B-i,ii). $\mathrm{CaH}_{2}$ films form spontaneously from contact between Ca metal and the $\mathrm{Ca}\left[\mathrm{BH}_{4}\right]_{2} / \mathrm{THF}$ electrolyte and throughout deposited films during plating, contributing in part to the suppression of continued electrolyte decomposition. The accumulation of $\mathrm{CaH}_{2}$ was demonstrated to saturate at the surface at open-circuit potential (OCP) (Figures 4B-iii,iv), but the reasonably thick films also contributed to increased overpotentials of stripping and losses in Coulombic efficiency. Ta and coworkers demonstrated that the deposition of $\mathrm{Ca}$ in $\mathrm{Ca}\left[\mathrm{BH}_{4}\right]_{2} / \mathrm{THF}$ electrolytes at inert $\mathrm{Au}$ and $\mathrm{Pt}$ substrates likely involves an initial slow chemical step in a chemical-electrochemical deposition mechanism (Ta et al., 2019). Unlike the above work of Wang et al., wherein spontaneous reaction between deposited $\mathrm{Ca}$ metal and THF in the electrolyte led to $\mathrm{CaH}_{2}$ formation, the preceding chemical step at inert $\mathrm{Au} / \mathrm{Pt}$ surfaces was ascribed to a hydride abstraction from the $\left[\mathrm{BH}_{4}\right]^{-}$anions (not THF) and was found to be substrate-dependent. By simulation of voltammetry at $\mathrm{Au}$ and $\mathrm{Pt}$ microelectrodes, the rate constant of the chemical step at Au was estimated as ca. 10 times smaller than that for $\mathrm{Pt}$, contributing to smooth/uniform or island-like deposits at $\mathrm{Au}$ and $\mathrm{Pt}$, respectively. This is attributed to the slower rate of the chemical step allowing time for lateral diffusion and well-distributed hydride on the Au surface, whereas less lateral diffusion can occur during the more rapid accumulation of the adsorbed hydride on Pt.

While favorable Ca plating/stripping is achieved on the $\mathrm{Au}$ surface, demonstrating the requirement for a stable SEI-type phase that supports $\mathrm{Ca}^{2+}$ mobility, the anodic stability of a $\mathrm{Ca}$ $\left[\mathrm{BH}_{4}\right]_{2} / \mathrm{THF}$ electrolyte is only ca. $3 \mathrm{~V}$ vs. $\mathrm{Ca}^{2+} / \mathrm{Ca}$ (Wang et al., 2018a). As such, due to the reducing nature of $\left[\mathrm{BH}_{4}\right]^{-}$anions, such a formulation is likely to be incompatible with a $\mathrm{Ca}-\mathrm{O}_{2}$ electrochemical system. In this context, Li et al. and Shyamsunder et al. both demonstrated good room temperature Ca plating/ stripping using a $\mathrm{Ca}\left[\mathrm{B}(\mathrm{Ohfip})_{4}\right]_{2} \quad$ (Ohfip = hexafluroisopropoxide) salt in dimethoxyethane (DME) (Li et al., 2019; Shyamsunder et al., 2019). Shyamsunder et al. demonstrated the electrolyte can facilitate a Coulombic efficiency of Ca plating/stripping up to $92 \%$ at $\mathrm{Au}$ (Figure 4Ci) but suffered from moderately higher overpotentials $(0.3 \mathrm{~V}$ at $0.2 \mathrm{~mA} \mathrm{~cm}^{-2}$, Figure 4C-ii) and short circuit failure owing to dendritic growth of $\mathrm{Ca}$. Critically, both research groups reported good anodic stabilities for these electrolytes: 4.2 and $4.8 \mathrm{~V}$ vs. $\mathrm{Ca}^{2+} / \mathrm{Ca}$ for stainless steel and $\mathrm{Al}$, respectively, at $0.25 \mathrm{M}(\mathrm{Li}$ et al.); 3.8 and $4.1 \mathrm{~V}$ vs. $\mathrm{Ca}^{2+} / \mathrm{Ca}$ for $\mathrm{Au}$ and $\mathrm{Al}$, respectively, at $0.5 \mathrm{M}$ (Shyamsunder et al., Figure 4C-iii). Both groups reported significant $\mathrm{CaF}_{2}$ phases and, importantly, no evidence of $\mathrm{CaH}_{2}$ in the SEI films on $\mathrm{Ca}$ deposits. However, upon prolonged cycling (Shyamsunder et al.), persistent growth of $\mathrm{CaF}_{2}$ resulted in the surface passivation of the substrate electrodes. Furthermore, Shyamsunder et al. reported on the improved plating/stripping performance by doping the electrolyte with $0.1 \mathrm{M}$ of tetrabutylammonium chloride $\left(\left[\mathrm{Bu}_{4} \mathrm{~N}\right] \mathrm{Cl}\right)$, facilitating a conductivity enhancement that supported enhanced deposition and stripping rate capabilities, improving Coulombic efficiencies and improving the cycle lifetime of the cells. This effect was demonstrated by Ta et al. in their mechanistic study of Ca plating/ stripping in $\mathrm{Ca}\left[\mathrm{BH}_{4}\right]_{2} / \mathrm{THF}$ electrolytes (Ta et al., 2019). In addition to improving electrolyte conductivity, the authors highlighted similar plating/stripping enhancements by chloride additive that have been seen in $\mathrm{Mg}$ systems; however, the underlying explanation for improved plating/stripping and cell performances is yet to be fully explored. While this electrolyte formulation is limited with respect to growing surface passivation and solvent volatility, the application of a novel salt toward supporting $\mathrm{Ca}$ deposition/stripping with good oxidative stability represents an important step for the use of Ca metal anodes in high-voltage systems. The reduction in susceptibility of electrolyte components to continued reductive decomposition and the introduction of additives to understand and control SEI formation should be key strategies toward developing $\mathrm{Ca}$ anode viability.

\section{Ionic Liquids for Ca Deposition}

The utilization of ILs as alternative nonaqueous electrolyte solvents to support $\mathrm{Ca}$ plating/stripping has also been explored in recent years. Shiga et al. explored the fabrication of a full $\mathrm{Ca}_{-} \mathrm{O}_{2}$ cell with an ether functionalized quaternary ammonium-based IL, [DEME] [TFSI] with $0.1 \mathrm{M} \mathrm{Ca}[\mathrm{TFSI}]_{2}$ (Shiga et al., 2017). Therein, while the full cell showed some evidence of reversibility with the use of a 2,2,6,6-tetramethylpiperidine-1-oxyl- (TEMPO) functionalized cathode and combined with parasitic decomposition reactions on charging (discussed in the following sections), the IL-based electrolyte did present evidence of $\mathrm{Ca}$ plating/stripping at a $\mathrm{Pt}$ substrate at $60{ }^{\circ} \mathrm{C}$ with faster scan rates. Under slower scan rates, where freshly deposited Ca can react with the electrolyte to a greater extent, stripping was reduced even further or not observed at all. However, even at higher scan rates (100-200 $\left.\mathrm{mV} \mathrm{s}^{-1}\right)$, the Coulombic efficiency of the plating/ stripping process was less than $10 \%$ and required very high overpotentials (ca. $2 \mathrm{~V}$ vs. $\mathrm{Ca}^{2+} / \mathrm{Ca}$ ).

Subsequently, Biria et al. reported the room temperature plating/stripping of $\mathrm{Ca}$ in an ionic liquid electrolyte using 1ethyl-3-methylimidazolium trifluoromethanesulfonate with $1 \mathrm{M} \mathrm{Ca}\left[\mathrm{BF}_{4}\right]_{2}$ salt (Biria et al., 2020). Plating and stripping overpotentials of the $\mathrm{Ca}$ at a $\mathrm{Cu}$ substrate under galvanostatic control were initially substantial (ca. $\pm 4 \mathrm{~V}$ vs. $\mathrm{Ca}^{2+} / \mathrm{Ca}$ ) but stabilized with successive cycling to $1 \mathrm{~V}$ vs. $\mathrm{Ca}^{2+} / \mathrm{Ca}$, attributed to SEI formation by the authors. Therein, persistent quantities of $\mathrm{CaF}_{2}$ and $\mathrm{CaS}$ are identified before and after stripping steps. Additionally, Coulombic efficiencies of Ca plating/stripping in this formulation stabilized to approximately 56\% after the initial three stabilization cycles. Owing to the attractive properties presented by the potential use of ILs as electrolyte solvents in metal-air batteries, these works represent noteworthy preliminary work in this area. Further development of IL-based electrolytes, in the context of Ca$\mathrm{O}_{2}$ cells, should concern the realization of low overpotential plating and stripping with considerable improvements to Coulombic efficiencies. 


\section{Summary of Electrolyte Development and Outlook for Calcium Deposition}

Within the general context of electrolyte development for electrochemical cells based on the use of Ca-metal anodes, significant developments have been achieved in only the last $4-5$ years. While previously considered as somewhat a practical impossibility, these recent developments revealed the feasibility of electrodeposition and dissolution with moderate overpotentials and good efficiencies. The timeline for various scientific achievements for $\mathrm{Ca}$ (and $\mathrm{Mg}$ ) plating/stripping is summarized in Figure 3. Electrolytes based on borate-based anions have been demonstrated with the most success at calcium anodes, supporting the formation of $\mathrm{Ca}^{2+}$ conductive surface films on the metal. While high temperatures were critical in the initial demonstration of more conventional $\left[\mathrm{BF}_{4}\right]^{-}$-based salts, achieving reversible Ca plating/stripping at room temperature was an important step in understanding the viability of $\mathrm{Ca}$ cells. Depending on the salt/solvent combinations selected, $\mathrm{CaF}_{2}$ and $\mathrm{CaH}_{2}$ have been found to be important SEI components arising from electrolyte reducing reactions at $\mathrm{Ca}$ anodes. However, continuous accumulation of $\mathrm{CaF}_{2}$ appears to eventually build passivation of the interface; thus controlling the first stages of SEI formation with, for example, the introduction of reactive additives or pretreatment steps should be considered. Further understanding of critical SEI components in different electrolytes and their effects on deposition/dissolution efficiency, stability, and morphology will be an important next step to aid in the design of new strategies for improving the reliability of the $\mathrm{Ca}$ /electrolyte interface. Additionally, methods for the promotion of salt solubility and electrolytic conductivity are vital for future material development.

However, applying the context of $\mathrm{Ca}-\mathrm{O}_{2}$ battery chemistry (and the wider general context of utilizing high-voltage cathodes), limitations in oxidative stability of the electrolyte materials are important to consider. Due to the challenges in recharging various $\mathrm{M}$-oxide deposits, cell voltages in excess of $3.5 \mathrm{~V}$ are expected (even with potential redox mediators). In addition, stability toward reactive intermediates and products (not currently fully understood for $\mathrm{Ca}$ ) is essential for any candidate electrolyte. Consequently, electrolytes based on the $\left[\mathrm{BH}_{4}\right]^{-}$anion are highly unlikely to be suitable for use in Ca$\mathrm{O}_{2}$ cells as oxidative decomposition of the THF/ $\mathrm{Ca}\left[\mathrm{BH}_{4}\right]_{2}$ occurs just below $3 \mathrm{~V} \mathrm{vs.} \mathrm{Ca}^{2+} / \mathrm{Ca}$. Likewise, the understood reactivity of organic carbonates toward superoxide radical intermediates negates any formulations based on these solvents for further application in $\mathrm{Ca}-\mathrm{O}_{2}$.

Of the materials studied and discussed for Ca plating/stripping in this work, the fluorinated alkyl borate salt $\mathrm{Ca}\left[\mathrm{B}(\mathrm{Ohfip})_{4}\right]_{2}$ and its use in glyme solvents could be an interesting candidate material for initial studies of the ORR/OER. A reasonably high oxidative stability ( $>3.5 \mathrm{~V}$ depending on the electrode material) combined with no directly obvious protons susceptible to attack by superoxide radical intermediates is encouraging. Furthermore, owing to the good anodic stability ( $4 \mathrm{~V}$ vs. $\mathrm{Mg}^{2+} / \mathrm{Mg}$ ) of the $\mathrm{Mg}$ $\mathrm{FPB} /$ diglyme electrolyte, discussed in a previous section (Luo et al., 2019a), as well as the improved plating/stripping efficiency and reductive stability at $\mathrm{Mg}$ metal compared to the $\mathrm{Mg}$
$\left[\mathrm{B}(\mathrm{Ohfip})_{4}\right]_{2}$ salt, the related $\mathrm{Ca}$ analog (i.e., Ca-FPB) should be considered for future investigations of both $\mathrm{Ca}$ plating/ stripping and $\mathrm{Ca}-\mathrm{O}_{2}$ electrochemistry. However, for extended practical full-cell use, electrolyte volatility must be a considered factor. In this regard, low chain length glymes (like dimethoxyethane) are unlikely to be practically suitable. Conversely, while much effort is required to improve the reversibility of plating/stripping in the IL-based electrolytes discussed here, the nonvolatility of ILs addresses the critical aspect of electrolyte evaporation under conventional cell operation.

\section{OXYGEN REDUCTION AND EVOLUTION REACTIONS IN NONAQUEOUS ELECTROLYTES}

Understanding the fundamental electrochemistry and ORR/OER mechanisms is essential for the development of nonaqueous metal-air batteries (Johnson et al., 2014). The ORR in many nonaqueous electrolytes, in the absence of $\mathrm{M}^{\mathrm{n}+}$ cations, can be quite reversible (or quasi reversible) via a one-electron transfer process (Sawyer et al., 1983; Aldous and Hardwick, 2014). When the alkali metal cation, including lithium, sodium, or potassium, is present, the oxygen reduction and evolution behaviors change significantly and the reversibility can decrease. This change can be ascribed to the surface passivation by the insoluble metal oxygen species formed by various reactions between the metal cation and superoxide radical anions (and various intermediary species) (De Giorgio et al., 2011; Khan and Zhao, 2014; Wang et al., 2018b; Sheng et al., 2018). However, the utilization of these monovalent alkali metal cations in rechargeable metal-air batteries is still promising with the assistance of appropriate electrolytes (Johnson et al., 2014), electrocatalysts (Yang et al., 2013), or additives like redox mediators (Kundu et al., 2015), which lead to improved ORR and OER performance. However, for divalent alkaline-earth cations, the reversibility of the ORR and OER can be significantly different and research is relatively limited to date. The ORR in $\mathrm{Mg}^{2+} / \mathrm{Ca}^{2+}$. containing electrolytes is scarcely reversible, as described in the introduction.

\section{Magnesium \\ Oxygen Electrochemistry in $\mathrm{Mg}^{2+}$-Containing Ionic Liquids}

Investigations of the ORR and OER in ILs have been carried out in the past decade. AlNashef et al. first demonstrated that the superoxide ion can be stable in ILs without the presence of impurities (AlNashef et al., 2001). Among various ILs, $\left[\right.$ Pyrr $\left._{14}\right][$ TFSI $] \quad\left(\right.$ Pyrr $_{14}=1$-butyl-1-methylpyrrolidinium $)$ receives much attention as it exhibits relatively good stability with respect to the superoxide ion (enabling good reversibility of the ORR on the timescale of conventional cyclic voltammetry experiments) and has been studied in $\mathrm{Li}-\mathrm{O}_{2}$ applications (Katayama et al., 2005; Monaco et al., 2013; Das et al., 2015; Neale et al., 2016). Behm's group probed the oxygen reduction electrochemistry on Au and GC electrodes in $0.1 \mathrm{M} \mathrm{Mg}[\mathrm{TFSI}]_{2}$ 
in $\left[\right.$ Pyrr $\left._{14}\right][$ TFSI], employing a three-electrode cell with forced electrolyte convection (Law et al., 2016). They reported that the addition of $\mathrm{Mg}$ salt renders the ORR irreversible, with the ORR current decaying quickly in the first few cycles. However, the appearance of a small anodic peak was observed after some CV cycles. When $\mathrm{CV}$ s were recorded in an expanded potential window (where the negative potential limit was extended), a more pronounced anodic peak appeared already in the first cycle. When combined with a series of $\mathrm{CV}$ experiments in varied potential ranges, the anodic peak, which is thought of as the OER, is related to the reduction process in a more negative potential region. Therein, the ORR is coupled with the formation of a surface film of $\mathrm{MgF}_{2}$ and other [TFSI] decomposition products that were found to build passivation at the electrodes interface and impede reaction kinetics. In this work, the authors do not observe any $\mathrm{MgO}$ or $\mathrm{MgO}_{2}$ ORR products by the postmortem XPS and they attributed this to a more favorable formation of $\mathrm{MgF}_{2}$ generated from reaction with the electrolyte.

Behm's group later published another work about $0.1 \mathrm{M} \mathrm{Mg}$ $[\mathrm{TFSI}]_{2}$ in $\left[\mathrm{Pyrr}_{14}\right][\mathrm{TFSI}] \mathrm{IL}$, where they studied the ORR and OER on a range of electrode materials, namely, $\mathrm{Pt}, \mathrm{Au}, \mathrm{GC}, \mathrm{Mn}_{2} \mathrm{O}_{3}$, and $\mathrm{MnO}_{2}$, in a rotating ring-disc electrode (RRDE) setup to gain more general insights (Bozorgchenani et al., 2018). However, in the $\mathrm{Mg}^{2+}$-containing IL, none of these electrode materials exhibited any OER feature and the ring electrode (held at $1 \mathrm{~V}$ vs. $\mathrm{Mg} / \mathrm{MgO}$ ) did not capture any intermediates either. During the cycling, the cathodic current dropped quickly as a result of the passivation layer. On the other hand, it is noticeable that the electrode surface was not totally passivated after some cycles, indicated by the emergence of a small OER peak related to superoxide reoxidation. The XPS results revealed that $\mathrm{MgO}_{2}$ composed a great portion of the passivation layer, which seems contradictory to the previous work where $\mathrm{MgF}_{2}$ was the main component of the passivation layer (Law et al., 2016). However, although a number of additional tests were conducted, the authors were still not able to find parameters/conditions that resulted in the discrepancy between these two works.

In 2019, Behm's group reported a more comprehensive research work on the same IL, $\left[\right.$ Pyrr $\left._{14}\right][$ TFSI], where differential electrochemical mass spectrometry (DEMS) and in situ attenuated total reflectance-Fourier transform infrared (ATR-FTIR) measurements were simultaneously carried out in a thin-layer flow cell (Jusys et al., 2019). In the $\mathrm{O}_{2}$-saturated [Pyrr $\left.{ }_{14}\right][$ TFSI], two well-defined mass transport-controlled reduction current plateaus can be observed during the ORR, and the DEMS result suggests superoxide and peroxide species are the products. By contrast, only a tiny OER peak can be seen, which is attributed to the removal of ORR products by the flowing electrolyte. On the other hand, comparing the ATRFTIR results of $\mathrm{N}_{2}$ - and $\mathrm{O}_{2}$-saturated [ $\mathrm{Pyrr}_{14}$ ] [TFSI], the $-\mathrm{OH}-$ stretching mode (from water impurities) is more intense in the $\mathrm{O}_{2}$-enriched $\left[\mathrm{Pyrr}_{14}\right][\mathrm{TFSI}]$ on the negative scan. The authors suggest that it may result from the adsorbed (super)oxide anions formed during the ORR since water tends to adsorb preferably with adsorbed anions. Furthermore, two potentialdependent IR absorption bands, with one located between 1,000 and $1,100 \mathrm{~cm}^{-1}$ and the other at ca. $1,200 \mathrm{~cm}^{-1}$, are both related to superoxide and/or peroxide. After carefully studying $\mathrm{Mg}^{2+}$-free $\left[\mathrm{Pyrr}_{14}\right.$ ][TFSI] with saturated $\mathrm{N}_{2} / \mathrm{O}_{2}$, the $\mathrm{O}_{2}$-saturated [Pyrr $\left.{ }_{14}\right]\left[\right.$ TFSI] containing $0.1 \mathrm{M} \mathrm{Mg}[\mathrm{TFSI}]_{2}$ was examined under the same experimental conditions. The CV results are in agreement with previous results (see discussion above), where a serious passivation layer on the electrode is suggested. Again, DEMS results support that the main ORR product is $\mathrm{MgO}_{2}$, consistent with the previous work using ex situ XPS (Bozorgchenani et al., 2018). In addition, in situ IR reveals an interaction of water with $\mathrm{MgO}_{\mathrm{x}}$ or $\mathrm{MgF}_{2}$ formation (the latter observed in reference (Law et al., 2016)). This article, in many aspects, is in agreement with the previous two articles about the ORR in $\mathrm{Mg}^{2+}$-containing [Pyrr ${ }_{14}$ ][TFSI]. Besides, utilization of in situ IR spectroscopy is demonstrated to be beneficial to study the interplay between IL ions and the ORR intermediates.

\section{Oxygen Electrochemistry in $\mathrm{Mg}^{2+}$-Containing Organic Electrolytes}

Dimethyl sulfoxide (DMSO) is commonly selected as a suitable solvent for $\mathrm{O}_{2}$ electrochemistry due to its appreciable ability to stabilize reactive intermediates of ORR (Trahan et al., 2012), but it should be noted that the solvent, as well as the anions and electrode substrates, may be expected to influence the ORR/OER electrochemistry, including the onset potential, reaction mechanism, and product distribution. Baltruschat's group carried out a detailed investigation in order to elucidate the underlying mechanism of ORR in $0.4 \mathrm{M} \mathrm{Mg}\left[\mathrm{ClO}_{4}\right]_{2} / \mathrm{DMSO}$ (Reinsberg et al., 2016a). CVs and corresponding mass spectrometric CV (MSCV) were recorded with the DEMS technique for a few cycles without obvious deactivation of the electrode. However, no oxygen evolution is visible during the positive sweep, indicating the irreversibility of ORR (Figure 5A-i). The authors inferred this phenomenon could be explained by the decomposition of ORR products or intermediates by unknown chemical reactions. It is worth noticing that the ORR onset potential is close to the $\mathrm{O}_{2}{ }^{-}$formation rather than $\mathrm{MgO}_{2}$ formation (see Figure 5A-i). In this work, however, $\mathrm{MgO}_{2}$ or other peroxide species (instead of $\mathrm{MgO}$ ) was suggested to be the main ORR product during the cathodic polarization of CV on GC, $\mathrm{Au}$, and $\mathrm{Pt}$, whereas the partial formation of $\mathrm{MgO}$ was found on $\mathrm{Ru}$ and $\mathrm{Rh}$, according to the DEMS results (Figure 5A-ii). Combining the DEMS results and some kinetics investigation, the authors proposed an ORR mechanism (Figure 5A-iii) where $\mathrm{O}_{2}{ }^{-}$forms at the initial step, followed by the hypothesized $\mathrm{MgO}_{2}{ }^{+}$formation. Then, $\mathrm{MgO}_{2}$ forms via the second reduction, in competition with other chemical reactions. Herein, the authors suggested that it is improbable for the cations to have a strong impact on the noncharged $\mathrm{O}_{2}$ molecule as the onset of the ORR appears to be unaffected. In contrast, the cation does have a strong impact on the second reduction step, considering the ORR product distribution in electrolytes containing $\left[\mathrm{Bu}_{4} \mathrm{~N}\right]^{+}$or $\mathrm{Li}^{+}$, wherein peroxide cannot form in the former case but can be found in the latter. Therefore, the existence of a hypothetical superoxide-cation complex $\left(\mathrm{MgO}_{2}^{+}\right)$intermediate can rationalize why the type of cation has an impact on the reduction potential of the second electron transfer (corresponding to peroxide formation) instead of the 

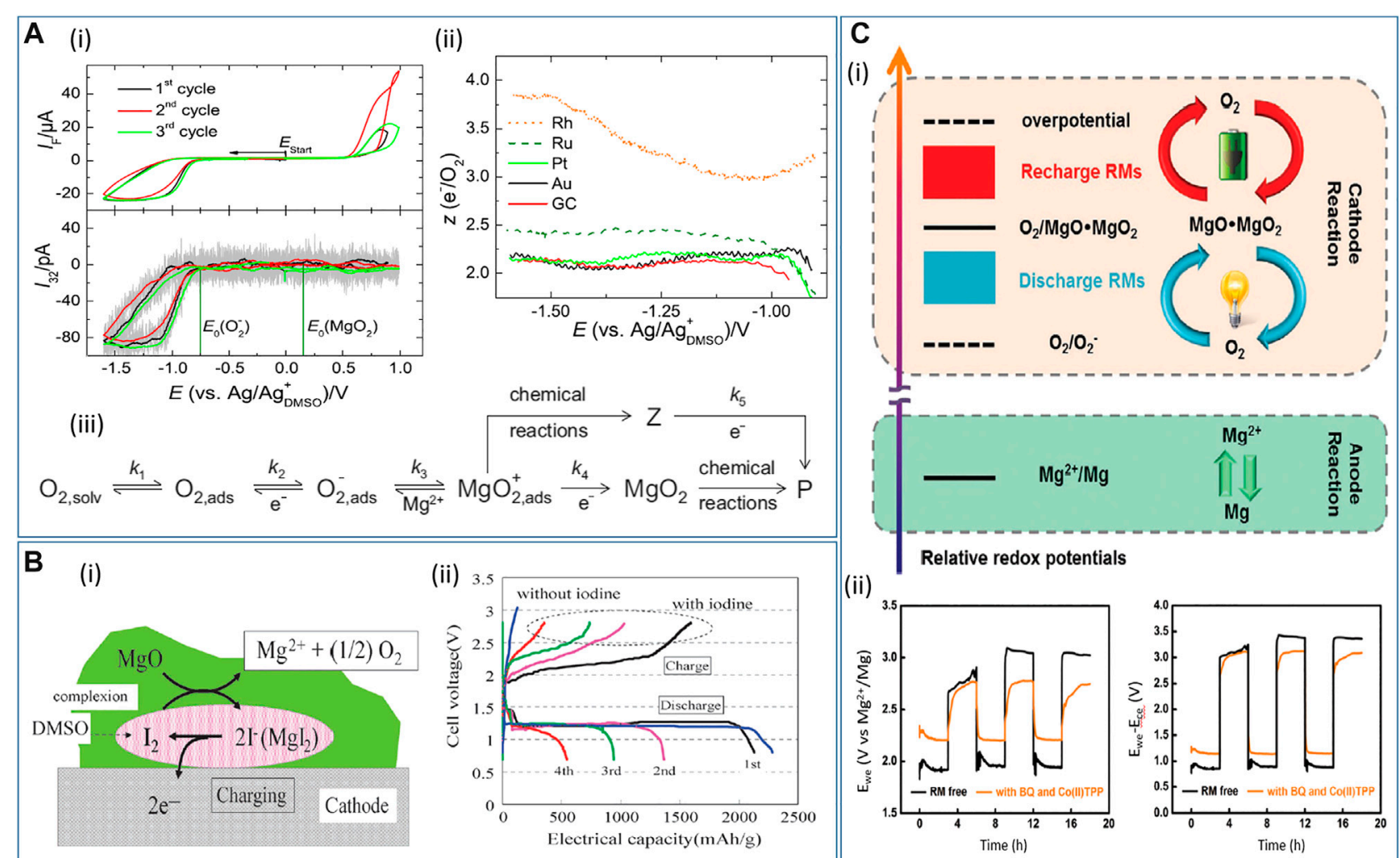

(ii)
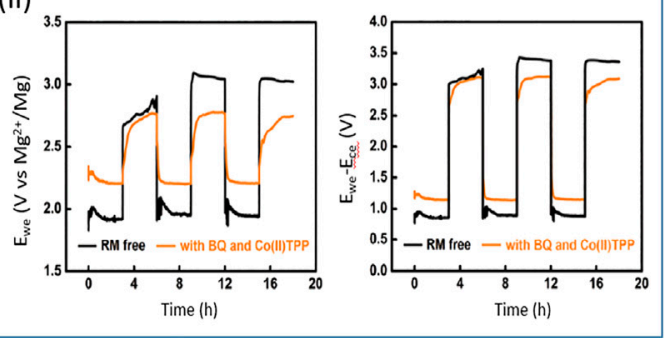

FIGURE 5 | (A-i) Subsequent CVs at $10 \mathrm{mV} \mathrm{s}{ }^{-1}$ and corresponding mass spectrometric $\mathrm{CVs}$ for $\mathrm{O}_{2}$ in $0.4 \mathrm{M} \mathrm{Mg}\left[\mathrm{ClO}_{4}\right]_{2} / \mathrm{DMSO}$ saturated with a mixture of Ar and $\mathrm{O}_{2}(80: 20)$ on Pt. (A-ii) Number of electrons z transferred per oxygen molecule on different electrode materials in $0.4 \mathrm{M} \mathrm{Mg}\left[\mathrm{ClO}_{4}\right]_{2} / \mathrm{DMSO}$ with $20 \% \mathrm{O}_{2}$ saturation. (A-iii) Proposed ORR mechanism on $\mathrm{Pt}$ in $\mathrm{Mg}^{2+}$-containing DMSO electrolyte with $\mathrm{k}_{i}$ being the rate constant of step $i$, $\mathrm{P}$ being the unknown final products, and $Z$ being an intermediate. Reproduced with permission from (Reinsberg et al., 2016a). (B-i) Proposed reaction mechanism of the charging process for $\mathrm{Mg}-\mathrm{O}_{2}$ cell using $\mathrm{I}_{2}$ as the redox mediator. (B-ii) Discharge-charge curves of $\mathrm{Mg}^{-\mathrm{O}_{2}}$ cell with $\mathrm{I}_{2}$ at $60{ }^{\circ} \mathrm{C}$. Reproduced with permission from (Shiga et al., 2013). (C-i) Operation principles of

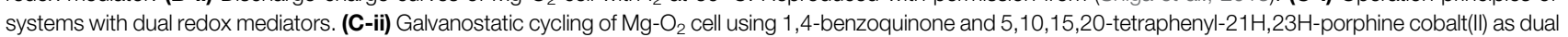
redox mediators. The left panel shows the voltage profile measured against the Mg reference electrode in a three-electrode configuration, whereas the right panel shows the voltage profile against the counter electrode in a two-electrode configuration. Reproduced with permission from (Dong et al., 2016).

ORR onset potential (corresponding to superoxide formation). Later, Baltruschat's group published another work concerning the influence of divalent cations on the ORR (Reinsberg et al., 2018). The ORR and OER in $\left.0.4 \mathrm{M} \mathrm{M}^{2} \mathrm{ClO}_{4}\right]_{2}(\mathrm{M}=\mathrm{Mg}, \mathrm{Ca}, \mathrm{Sr}$, $\mathrm{Ba}$ ) electrolytes were investigated on $\mathrm{Au}, \mathrm{Pt}$, and $\mathrm{GC}$ electrodes. Different from its analogs $\left(\mathrm{Ca}^{2+}, \mathrm{Sr}^{2+}, \mathrm{Ba}^{2+}\right)$, peroxide forms in $\mathrm{Mg}^{2+}$-containing DMSO on three different electrode materials according to the DEMS results. Conversely, the other divalent cations show some superoxide formation to various degrees on $\mathrm{Pt}$ and GC. Further elucidation of the difference in product distribution will be delivered in the section on $\mathrm{Ca}-\mathrm{O}_{2}$ electrochemistry. These two articles from the same group reported that the ORR/OER is scarcely reversible in the $\mathrm{Mg}\left[\mathrm{ClO}_{4}\right]_{2} / \mathrm{DMSO}$ electrolyte.

In 2015, Vardar et al. reported their study on the ORR discharge products in $\mathrm{Mg}-\mathrm{O}_{2}$ cell using $\mathrm{PhMgCl}-\mathrm{Al}[\mathrm{OPh}]_{3} /$ THF electrolyte (Vardar et al., 2015), since this electrolyte not only allows reversible plating/stripping at room temperature but has high oxidation stability above $4 \mathrm{~V}$ vs. $\mathrm{Mg}^{2+} / \mathrm{Mg}$. The measured OCP (ca. $2 \mathrm{~V}$ ) and operating cell voltage (ca. $1.5 \mathrm{~V}$ ) suggest free superoxide $\left(\mathrm{O}_{2}{ }^{-}\right)$forms in the first electrochemical step, followed by a chemical step where $\mathrm{MgO}_{2}$ forms and an $\mathrm{O}_{2}$ molecule is liberated. Then, $\mathrm{MgO}_{2}$ undergoes disproportionation into $\mathrm{MgO}$. The whole process is described in the following equations:

$$
\begin{aligned}
& \mathrm{O}_{2}+e^{-} \leftrightarrow \mathrm{O}_{2}^{-}\left(2.04 \mathrm{Vvs} \mathrm{Mg}^{2+} / \mathrm{Mg}\right) \\
& \mathrm{Mg}^{2+}+2 \mathrm{O}_{2}^{-} \leftrightarrow \mathrm{MgO}_{2}+\mathrm{O}_{2} \\
& 2 \mathrm{MgO}_{2} \leftrightarrow 2 \mathrm{MgO}+\mathrm{O}_{2}
\end{aligned}
$$

Thus, an ECC (electrochemical-chemical-chemical) mechanism is hypothesized. If $\mathrm{MgO}$ or $\mathrm{MgO}_{2}$ is generated directly via electrochemical reactions (i.e., four-/two-electron transfer processes), the recorded OCP and operating cell potential must be larger and thus closer to the theoretical voltages of $\mathrm{MgO}_{\mathrm{x}}\left(2.91 \mathrm{~V}\right.$ for $\mathrm{MgO}_{2}$ and $2.95 \mathrm{~V}$ for $\mathrm{MgO}$, see Table 1). The postmortem characterization of discharged air electrodes by Auger electron spectroscopy (AES) showed that the discharge product was a mixture of $\mathrm{MgO}$ and $\mathrm{MgO}_{2}$, with the volume percentage being $70 \%$ and $30 \%$, respectively. After the air electrode was recharged, Raman and AES both revealed the preferential decomposition for $\mathrm{MgO}_{2}$ but rather limited 
decomposition for $\mathrm{MgO}$. All these works suggest that $\mathrm{MgO}_{2} / \mathrm{MgO}$ are not directly generated via electrochemical reactions but via multistep processes involving initial $\mathrm{O}_{2}^{-}$formation.

\section{Redox Mediators for Rechargeable $\mathrm{Mg}-\mathrm{O}_{2}$ Full Cells} In contrast to the ongoing research of the fundamental ORR/ OER electrochemistry, redox mediators (RMs) can be incorporated into the electrolytes to construct practical rechargeable $\mathrm{Mg}-\mathrm{O}_{2}$ batteries because of the resulting stable and efficient battery cycling. The redox mediator is a molecule dissolved in a solution that is oxidized into $\mathrm{RM}^{+}$(or other oxidized forms) upon recharging, which in turn oxidizes the ORR products $\mathrm{M}_{\mathrm{x}} \mathrm{O}_{\mathrm{y}}$, with itself being reduced back to RM. RMs have been widely demonstrated in metal-air battery research at the $\mathrm{Li}-\mathrm{O}_{2}$ and $\mathrm{Na}-\mathrm{O}_{2}$ cathode (Chen et al., 2013; Yin et al., 2015). Shiga and coworkers first demonstrated a rechargeable $\mathrm{Mg}-\mathrm{O}_{2}$ cell at an elevated temperature $\left(60{ }^{\circ} \mathrm{C}\right)$, using iodide $\left(\mathrm{I}^{-}\right)$as the RM (Shiga et al., 2013). In this work, the proposed catalysis mechanism suggests that $\mathrm{I}^{-}$is oxidized to $\mathrm{I}_{3}{ }^{-}$upon charge and then $\mathrm{I}_{3}{ }^{-}$decomposes the discharge product $\mathrm{MgO}$ (Figure 5B-i). Although obvious capacity fading was manifested over merely four cycles (Figure 5B-ii), the rechargeability of the $\mathrm{Mg}-\mathrm{O}_{2}$ cell proved to be possible. Herein, it is worth noting that the authors only investigated the decomposition of $\mathrm{MgO}$ rather than other possible reaction intermediates (superoxide and peroxide species). Although $\mathrm{MgO}$ is the final discharge product and is the most thermodynamically favorable compound, many recent studies also suggested (su)peroxide species as possible products during the ORR, as discussed above. Therefore, the interaction between $\mathrm{Mg}\left(\mathrm{O}_{2}\right)_{2}$ or $\mathrm{MgO}_{2}$ and $\mathrm{RMs}$ and the resultant electrochemical response is also of great importance.

Another research article explored the simultaneous use of two RMs in a $\mathrm{Mg}-\mathrm{O}_{2}$ cell (working principles shown in Figure 5C-i), one for discharge and the other for recharge (Dong et al., 2016). More specifically, the discharge redox mediator (1,4benzoquinone, BQ) promotes the formation of $\mathrm{MgO}_{2}$ or $\mathrm{MgO}$ and limits the superoxide formation, which thereby alleviates the ORR overpotentials. Additionally, the presence of BQ as a discharge $\mathrm{RM}$ can produce small-sized, uniform $\mathrm{MgO}_{2} / \mathrm{MgO}$ particles on the cathode, which could be able to increase the available capacity of $\mathrm{Mg}-\mathrm{O}_{2}$ cells. On the other hand, the recharge $\mathrm{RM} \quad(5,10,15,20$-tetraphenyl-21H,23H-porphine cobalt(II), Co(II)TPP) facilitates the decomposition of discharge products, confirmed by SEM and XPS. Overall, the charge-discharge gap is decreased by $0.6 \mathrm{~V}(0.3 \mathrm{~V}$ for each process, see the left panel in Figure 5C-ii), saving much energy wasted for sluggish kinetics of both oxygen electrochemistries. Note that, in a two-electrode configuration (the right panel in Figure 5C-ii), some overpotentials can be caused by the passivation of $\mathrm{Mg}$ counter electrode, which results in an underestimated round-trip efficiency. Furthermore, the long-term stability of any RMs at the anode interface requires significant consideration when investigating their application. However, this research gives the proof-of-concept demonstration that two different RMs can be applied at once to enhance the fullcell performance.

\section{Calcium \\ Oxygen Electrochemistry in $\mathrm{Ca}^{2+}$-Containing Electrolytes}

The earliest report of a system based on electrochemical reactions of $\mathrm{Ca}$ and $\mathrm{O}_{2}$ detailed the use of a molten salt electrolyte (29 mol\% $\mathrm{CaO}, 71 \mathrm{~mol} \% \mathrm{CaCl}_{2}$ with $\mathrm{ZrO}$ ) at $850{ }^{\circ} \mathrm{C}$, a CaSi alloy anode, and a perovskite positive electrode (Pujare, 1988). Fabricated cells were cycled at $850-900^{\circ} \mathrm{C}$ presenting cell voltages in the range of ca. 1-2 V; while no characterization of products is reported, the authors describe the full-cell electrochemistry as in the following equation:

$$
2 \mathrm{CaSi}+1 / 2 \mathrm{O}_{2} \leftrightarrow \mathrm{CaO}\left(\text { in } \mathrm{CaCl}_{2}\right)+\mathrm{CaSi}_{2}
$$

More recently, while remaining relatively unexplored compared to analogous $\mathrm{Mg}-\mathrm{O}_{2}$ systems, several works focusing on the effect of $\mathrm{Ca}^{2+}$ on the ORR/OER and the investigation into nonaqueous $\mathrm{Ca}-\mathrm{O}_{2}$ full cells have been reported. Baltruschat's group conducted the first detailed investigations of the nature of electrochemical oxygen reduction within liquid nonaqueous $\mathrm{Ca}^{2+}$-containing electrolytes, namely, $\mathrm{Ca}\left[\mathrm{ClO}_{4}\right]_{2}$ salts in DMSO (Reinsberg et al., 2016b). In this work, a combined series of CV, DEMS, and RRDE experiments are described at different electrode substrates to assess the ORR/OER. While the formation of $\mathrm{CaO}_{2}$ (calcium peroxide) is favored at $\mathrm{Au}$, with no evidence of any reversibility, $\mathrm{Ca}\left(\mathrm{O}_{2}\right)_{2}$ (calcium superoxide) is the dominant product of ORR at GC and Pt (as well as Rh and $\mathrm{Ru}$ ). Interestingly, the two-electron (per mole $\mathrm{O}_{2}$ ) reduction at $\mathrm{Au}$, attributed to peroxide formation, is not coupled with passivation and deactivation of the surface (i.e., no large hysteresis after the potential sweep is reversed), unlike $\mathrm{Li}^{+} / \mathrm{DMSO}$ systems. However, the reasons for the preferential formation of $\mathrm{CaO}_{2}$ at $\mathrm{Au}$ is yet to be explored. For the Pt and GC electrodes, DEMS measurements combined with a secondary detection electrode held at oxidative potentials, and the analogous RRDE configuration experiments, confirmed the reoxidation of dissolved superoxide species to be approaching $90 \%$ of $\mathrm{O}_{2}$ species reduced during the ORR at the reducing Pt/GC electrodes (Figure 6A). The secondary working electrode, an Au-sputtered Teflon membrane held close to the mass-spectrometer, reduced the total quantity of $\mathrm{O}_{2}$ consumed during cyclic voltammetry (Figure 6A-iii), indicating significant regeneration of molecular $\mathrm{O}_{2}$ from the oxidation of dissolved species. In combination with a degree of reoxidation of precipitated species at high voltages, these results indicate high Coulombic efficiency and good chemical reversibility of the ORR at Pt/GC. However, the significant overpotentials required for oxidation of the dissolved superoxide indicates that this is not free $\mathrm{O}_{2}{ }^{-}$(or loosely interacting) in solution, but rather the authors describe likely formation of contact ion pairs in solution with the dissolved $\mathrm{Ca}^{2+}$.

In a subsequent study by Baltruschat's research group, the effect of different alkaline-earth cations on the ORR/OER in DMSO-type electrolytes was demonstrated, as discussed initially in the context of $\mathrm{Mg}^{2+}$ electrolytes in the previous section 


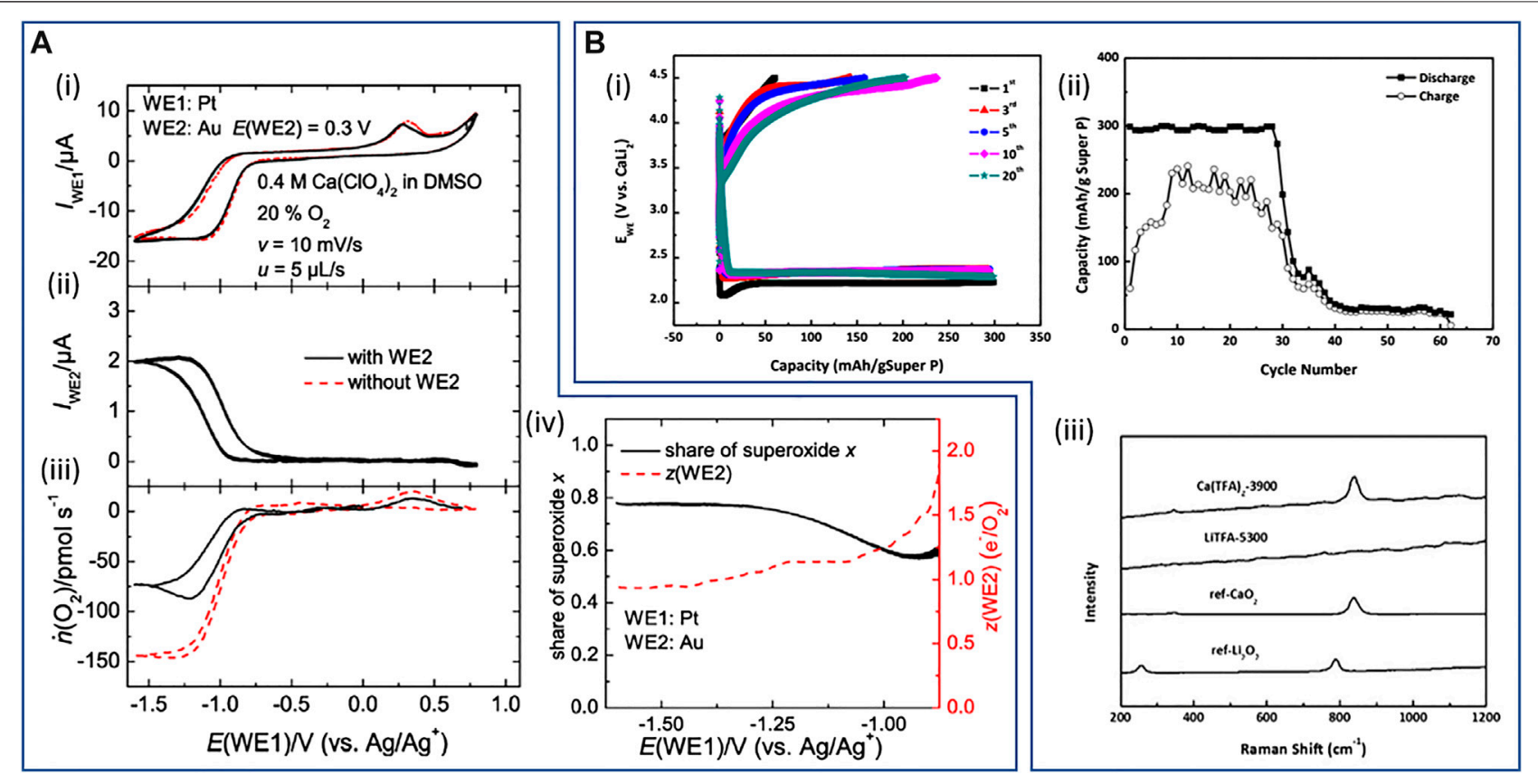

FIGURE 6 | (A) Identification of the soluble products via DEMS using $0.4 \mathrm{M} \mathrm{Ca}\left[\mathrm{ClO}_{4}\right]_{2} / \mathrm{DMSO}$ saturated with a mixture of $80 \%$ Ar and $20 \%$ O: (i) cyclic voltammograms at the Pt-working electrode (WE) with (black) and without (red) the use of an Au-sputtered Teflon membrane $(E(W E 2)=0.3 \mathrm{~V})$ in the detection compartment. (ii) Faradaic currents at the sputtered Teflon membrane. (iii) Corresponding flow of oxygen $\dot{n}\left(\mathrm{O}_{2}\right)$. (iv) Resulting electron numbers at the second working electrode (black) and share of superoxide x (red) calculated. (A) Reproduced with permission from (Reinsberg et al., 2016b). Copyright 2016 American Chemical Society. (B) Intermetallic CaLi $\mathrm{i}_{2}-\mathrm{O}_{2}$ batteries: (i) voltage profile of galvanostatic cycling and (ii) capacity retention of $\mathrm{CaLi}_{2}-\mathrm{O}_{2}$ cell using $0.1 \mathrm{M} \mathrm{Ca}[\mathrm{OTf}]_{2} / \mathrm{TEGDME}$ at a

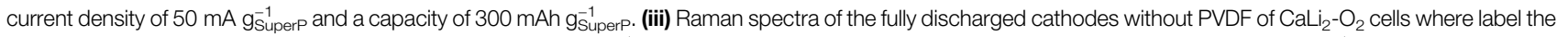
salt used and the number indicate the discharge capacity (mAh gsuperp). Discharged $\mathrm{Ca}[\mathrm{OTf}]_{2}$ (or Ca[TFA $]_{2}$ ) cell shows a clear band at $840 \mathrm{~cm}^{-1}$ in agreement with the reference spectra of $\mathrm{CaO}_{2}$. (B) Reproduced with permission from (Kim et al., 2020).

(Reinsberg et al., 2018). As per the previous investigation, peroxide remains the dominant product at $\mathrm{Au}$ electrodes in DMSO electrolytes containing $\mathrm{Ca}^{2+}$ as well as $\mathrm{Mg}^{2+}, \mathrm{Sr}^{2+}$, and $\mathrm{Ba}^{2+}$ (where $\left[\mathrm{ClO}_{4}\right]^{-}$was used as the salt counter-anion in all electrochemical measurements). However, while the onset of $\mathrm{O}_{2}$ reduction at $\mathrm{Pt}$ and GC remained consistent, the products of ORR were found to be highly dependent on the divalent cation. Therein, the tendency for peroxide formation over superoxide (as per the number of electrons per mole of $\mathrm{O}_{2}$ consumed) increases from $\mathrm{Ca}^{2+}<\mathrm{Sr}^{2+}<\mathrm{Ba}^{2+} \approx \mathrm{Mg}^{2+}$, such that superoxide dominates in $\mathrm{Ca}^{2+}$-containing systems and exclusively peroxide forms in the presence of $\mathrm{Mg}^{2+}$. The prevalence of superoxide or peroxide formation in these DMSO-based electrolytes is attributed, in part, to the type of interactions between superoxide generated in the first electron transfer and the cation at the electrode interface. The authors suggest that strongly polarizing cations with a large acceptor number (AN) may, by the withdrawal of electron density, polarize the superoxide radical anion and facilitate the second electron transfer. However, since there are no AN data available for $\mathrm{Ca}^{2+}\left(\right.$ or $\left.\mathrm{Sr}^{2+}\right)$, these trends were only compared for $\mathrm{Mg}^{2+} / \mathrm{Ba}^{2+}$ with $\mathrm{Li}^{+}$and $\mathrm{Na}^{+}$cations and it remains to be seen if this parameter would also describe the very different behavior of the $\mathrm{Ca}^{2+}$ electrolyte.

\section{$\mathrm{Ca}-\mathrm{O}_{2}$ Full Cells}

The construction of $\mathrm{Ca}-\mathrm{O}_{2}$ full cells relies on the ability to stabilize and control both challenging interfaces for Ca-metal plating/stripping and the ORR/OER. Formulation of electrolytes suitable for both environments remains a challenge for all of the metal- $\mathrm{O}_{2}$ battery chemistries; however, given the previous discussions of recent developments in these fields, such examples pertaining to $\mathrm{Ca}$ are still limited. The first such example made use of an IL-based electrolyte coupled with a RM-functionalized cathode framework and a Ca-metal chip anode, all held at $60^{\circ} \mathrm{C}$ (Shiga et al., 2017). The electrolyte was a [DEME][TFSI] IL with $0.1 \mathrm{M} \mathrm{Ca}[\mathrm{TFSI}]_{2}$ and the redox mediator was TEMPO grafted to a polymer backbone. Herein, the reaction on discharge under an $\mathrm{O}_{2}$ atmosphere was attributed to the formation of $\mathrm{CaO}$ at the cathode with greater than 1,500 $\mathrm{mAh}$ $\mathrm{g}^{-1}$ capacity at ca. $1.8 \mathrm{~V}$ on the first discharge. Upon charging, gas evolution analysis (by gas chromatography-mass spectrometry, GC-MS) demonstrated that oxidation of discharge products formed under $\mathrm{O}_{2}$ was possible in the presence of the TEMPOgroup RM. However, the charge/discharge efficiency fell in the range of $60-80 \%$, and the observed significant capacity fade was attributed primarily to anode stability/reversibility issues. While the IL-based electrolyte somewhat facilitates plating/stripping, as discussed in the earlier section, large overpotentials (ca. $2 \mathrm{~V}$ ) and 
poor efficiencies $(<10 \%)$ at the Ca-metal interface reduced cell voltages and led to rapid cell failure. Significant volumes of $\mathrm{H}_{2}$ gas were also evolved during charging of the cell, likely originating from important routes to the decomposition of the electrolyte that would impact cell operation.

In a recent attempt to alleviate issues pertaining to the reactivity and conductivity of $\mathrm{Ca}$ interfaces, while enabling the use of more conventional electrolyte systems for the benefit of cathode processes, the use of an intermetallic $\mathrm{CaLi}_{2}$ alloy electrode has been employed in full $\mathrm{Ca} / \mathrm{Li}-\mathrm{O}_{2}$ cells (Kim et al., 2020). In conjunction with a simple carbon black (Super P)-based cathode, the $\mathrm{CaLi}_{2}$ alloy anode supports full-cell cycling under $\mathrm{O}_{2}$ with a tetraethylene glycol dimethyl ether (TEGDME)/ trifluoromethanesulfone ([OTf $]^{-}$) electrolyte with $1 \mathrm{M} \mathrm{Li}[\mathrm{OTf}]$ or $0.1 \mathrm{M} \mathrm{Ca}[\mathrm{OTf}]_{2}$. While the majority of testing relates to the use of the $\mathrm{Li}$-salt electrolytes, wherein the $\mathrm{CaLi}_{2}$ alloy anode supports cycling performances comparable to $\mathrm{Li}$-metal, $\mathrm{CaLi}_{2}-\mathrm{O}_{2}$ cells employing Ca-electrolytes were able to cycle for more than 20 discharge/charge cycles (Figure 6B-i,ii). Reversible cycling was, therein, attributed to the formation of $\mathrm{CaO}_{2}$ at the cathode confirmed by Raman spectroscopy (Figure 6B-iii) and XRD and XPS analysis. Notably, cycling was reported under comparatively low current density and capacity regimes due to the poor conductivity of this Ca-based electrolyte formulation. The full $\mathrm{CaLi}_{2}-\mathrm{O}_{2}$ cell employing $\mathrm{Ca}[\mathrm{OTf}]_{2}$ did, however, support a large single discharge capacity up to $5,300 \mathrm{mAh} \mathrm{g}^{-1}$ (based on mass of carbon cathode with a $2 \mathrm{~V}$ (vs. $\mathrm{CaLi}_{2}$ ) cut-off limit). For both single salt electrolyte systems, the authors present evidence of the other cation at the cathode after cycling in various reaction products, demonstrating dissolution of both $\mathrm{Ca}$ and $\mathrm{Li}$ from the alloy anode occurs. While this factor may complicate prolonged cycling of full cells, the application of dual electrolytes containing $\mathrm{Ca}^{2+}$ and $\mathrm{Li}^{+}$warrants further investigations. Critically, this work highlights how the $\mathrm{CaLi}_{2}$ alloy anode enables the possibility of employing commercially available electrolyte components to facilitate both the Ca plating/stripping steps and the ORR/ OER in the same cell. Dedicated optimization of the electrolyte components to increase $\mathrm{Ca}^{2+}$ solubility (beyond $0.1 \mathrm{M}$ ) and ionic conductivity could further expand the performance and cyclability of such $\mathrm{CaLi}_{2}-\mathrm{O}_{2}$ systems.

\section{Summary of Oxygen Electrochemistry in $\mathrm{Mg}^{2+}$ / $\mathrm{Ca}^{2+}$-Containing Electrolytes and Future Outlook}

The electrochemistry of the ORR and OER in aprotic electrolytes containing $\mathrm{Mg}^{2+}$ and $\mathrm{Ca}^{2+}$ divalent metal cations remains in the early stages of investigation. So far, Baltruschat's group has conducted a series of important fundamental investigations on the effects of divalent metal ions (mainly $\mathrm{Mg} / \mathrm{Ca}$ and one including $\mathrm{Sr} / \mathrm{Ba}$ ) on the $\mathrm{O}_{2}$ electrochemistry in DMSO. Therein, reaction mechanisms and product formation were shown to be dependent on substrate and cation species within the DMSO. Additionally, analogous to Li- and Na-based $\mathrm{M}-\mathrm{O}_{2}$ chemistry, the chosen solvent is also expected to affect these processes via solvation effects on the metal cations and the reaction intermediates at the electrode interface. Such mechanistic investigations still need to be expanded in more electrolyte systems to explore any general applicability and, subsequently, to inform the design of new materials/substrates toward minimizing passivation and promoting reversibility of the reactions. Furthermore, ILs have been demonstrated as promising candidates to accommodate the oxygen electrochemistry for $\mathrm{Mg} / \mathrm{Ca}$; however, in addition to solubility and transport limitations, such investigations suggest that the incorporation of RMs or effective electrocatalysts into the air electrode would be required to overcome passivation of the interface.

The nature of the discharge process and the final product at the cathode interface is critical for determining cell capacity and rechargeability in $\mathrm{M}-\mathrm{O}_{2}$ cells. For $\mathrm{Li} / \mathrm{Na} / \mathrm{K}-\mathrm{O}_{2}$ chemistries, the monovalent cation superoxides $\left(\mathrm{MO}_{2}, \mathrm{M}=\mathrm{Li}^{+}, \mathrm{Na}^{+}, \mathrm{K}^{+}\right)$play a pivotal role in determining, to different degrees, the discharge performance (ORR). For example, the solvation of $\mathrm{LiO}_{2}$ reaction intermediate has been found to affect how the final product $\mathrm{Li}_{2} \mathrm{O}_{2}$ can precipitate on the air cathode (Johnson et al., 2014); $\mathrm{NaO}_{2}$ can make up a significant part of the discharge products (Ortiz-Vitoriano et al., 2015); $\mathrm{KO}_{2}$ is the sole discharge product (Yu et al., 2017). In contrast, the dependence of the ORR on the superoxide (as product or reaction intermediate) has not been demonstrated in the comparative divalent $\mathrm{Mg} / \mathrm{Ca}$ systems, and the formation of the peroxide and oxide species are primary products. The only exception is $\mathrm{Ca}\left(\mathrm{O}_{2}\right)_{2}$, which has been reported to form as the primary product on various working electrodes (aside from $\mathrm{Au}$ ). However, this is only observed in the DMSO-based electrolyte, and the explanation is not yet fully understood. In order to obtain more information about the effect of electrolytes on the ORR/OER, the desired product distribution, and to ascertain critical stability information, operando spectroscopic investigations of the air-cathode interface in more electrolyte systems (DMSO, acetonitrile, ether, glyme, etc.) should be the focus of future research. Nevertheless, progress is highly dependent on the development of suitable $\mathrm{Mg}$ and $\mathrm{Ca}$ salts that have an appreciable solubility in these solvents to provide sufficient ionic conductivity.

On the other hand, the oxygen reduction is still rather irreversible in $\mathrm{Mg} / \mathrm{Ca}$ systems compared with the $\mathrm{Li} / \mathrm{Na} / \mathrm{K}$ analogs, probably due to both the thermodynamically less favorable decomposition of ORR products and the more sluggish OER kinetics. To be more specific, $\mathrm{MgO}_{2} / \mathrm{MgO}$ and $\mathrm{CaO}_{2} / \mathrm{CaO}$, main discharge products in $\mathrm{Mg} / \mathrm{Ca}$ systems, are thermodynamically much more stable than $\mathrm{LiO}_{2} / \mathrm{Li}_{2} \mathrm{O}_{2}, \mathrm{NaO}_{2} /$ $\mathrm{Na}_{2} \mathrm{O}_{2}$, and $\mathrm{KO}_{2}\left(\Delta \mathrm{G}^{\circ}=-230 /-570.8 \mathrm{~kJ} \mathrm{~mol}^{-1}\right.$ for $\mathrm{LiO}_{2} / \mathrm{Li}_{2} \mathrm{O}_{2}$, $\Delta \mathrm{G}^{\circ}=-218.8 /-449.7 \mathrm{~kJ} \mathrm{~mol}^{-1}$ for $\mathrm{NaO}_{2} / \mathrm{Na}_{2} \mathrm{O}_{2}, \Delta \mathrm{G}^{\circ}=$ $-239.4 \mathrm{~kJ} \mathrm{~mol}^{-1}$ for $\mathrm{KO}_{2}, \Delta \mathrm{G}^{\circ}=-567.8 /-568.9 \mathrm{~kJ} \mathrm{~mol}^{-1}$ for $\mathrm{MgO}_{2} / \mathrm{MgO}$, and $\Delta \mathrm{H}^{\circ}=-652^{\star} \mathrm{kJ} \mathrm{mol}^{-1}$ for $\mathrm{CaO}_{2}$ and $\Delta \mathrm{G}^{\circ}=$ $603.5^{\star} \mathrm{kJ} \mathrm{mol}^{-1}$ for $\mathrm{CaO}$; asterisk labeled value is for formation enthalpy since no $\Delta \mathrm{G}^{\circ}$ is available). Also, multiple-electron transfer (at least two electrons) during the OER can result in sluggish kinetics. Although rechargeable metal-air batteries in these systems can be realized using RMs, understanding the underlying mechanisms and how they are mediated by solvents, substrates, overpotentials, and discharge/charge rates is still essential to develop practically viable batteries. For instance, some studies suggested that the ORR in $\mathrm{Mg}^{2+}$. 
containing electrolytes proceeds via an inner-sphere route (Reinsberg et al., 2016a), while other articles observed an opposite behavior similar to the outer-sphere mechanism (Law et al., 2016). This difference in the observed ORR/OER mechanisms can cause confusion whether or not the electrocatalyst is needed, therefore impeding the design of proper air electrodes. On the other hand, having metal oxide as the final product in Mg-air or Ca-air batteries may not be ideal, although it delivers the largest discharge capacity and energy density. Considering the reversibility of the discharge product, the metal peroxide could be more desirable for rechargeable metal-air batteries (Smith et al., 2016). It has been well accepted that the properties of discharge products (composition, morphology, etc.), as well as their interaction with the electrolyte, can strongly influence the cell capacity and cycle life (Vardar et al., 2015). Therefore, designing the air cathode and electrolyte, which allows the targeted formation of desired ORR products, will be a future direction for investigations.

\section{CONCLUDING REMARKS}

Plating and stripping at Mg anodes have been studied for many years, with much progress being made within the past 2 decades. However, many reported electrolyte classes are expected to be incompatible in $\mathrm{M}-\mathrm{O}_{2}$ systems and for alternative high-voltage chemistries. Conversely, much of the evidence of successful $\mathrm{Ca}$ plating/stripping has arrived only in the previous 5 years and has been realized without comparative organometallic- or halide-based chemistries that may be expected to yield stability and corrosion issues. In light of the discussed developments, suggestions and recommendations have been made to inspire possible applications of some potentially suitable electrolytes in $\mathrm{M}-\mathrm{O}_{2}$ full cells, wherein pairing good oxidative stabilities and conductivities with low overpotential and efficient plating/stripping is a critical target for candidate electrolytes. Further understanding of the components that make for a good SEI on $\mathrm{Mg} / \mathrm{Ca}$ anodes should be prioritized to support design of improved materials. Recent works on the cathode (electro)chemistries have then been discussed to glean information from these mechanistic studies. Such fundamental

\section{REFERENCES}

Abdallah, T., Lemordant, D., and Claude-Montigny, B. (2012). Are room temperature ionic liquids able to improve the safety of supercapacitors organic electrolytes without degrading the performances?. J. Power Sources 201, 353-359. doi:10.1016/j.jpowsour.2011.10.115

Abraham, K., and Jiang, Z. (1996). A polymer electrolyte-based rechargeable lithium/oxygen battery. J. Electrochem. Soc. 143, 1-5. doi:10.1149/1. 1836378

Aldous, I. M., and Hardwick, L. J. (2014). Influence of tetraalkylammonium cation chain length on gold and glassy carbon electrode interfaces for alkali metaloxygen batteries. J. Phys. Chem. Lett. 5, 3924-3930. doi:10.1021/jz501850u

Aldous, I. M., and Hardwick, L. J. (2016). Solvent-mediated control of the electrochemical discharge products of non-aqueous sodium-oxygen electrochemistry. Angew Chem. Int. Ed. Engl. 55, 8254-8257. doi:10.1002/ anie. 201601615 investigations, in the very early stages compared to the ongoing discoveries in comparative $\mathrm{Li} / \mathrm{Na}-\mathrm{O}_{2}$ chemistries, are important especially for the continued optimization and control of the discharge and charge processes and, subsequently, designing suitable air cathodes therein. However, while degrees of reversibility have been observed in both $\mathrm{Mg}$ and $\mathrm{Ca}$ systems, only redox mediators show the potential ability to facilitate efficient ORR/OER during battery cycling. Consequently, the parallel development of electroactive redox mediator additives may be vital to support rechargeability of the ORR/OER in a meaningful way and their effects on the anode processes should be considered. To date, research on $\mathrm{Mg} / \mathrm{Ca}$ has been still quite limited in comparison with $\mathrm{Li} / \mathrm{Na} / \mathrm{K}$, particularly for the air cathode. More electrolyte systems containing various salts/solvents are required to be probed, in order to obtain more generalized understandings of important processes in divalent metal-air batteries and deeper insights into their underlying chemical nature.

\section{AUTHOR CONTRIBUTIONS}

Y-TL: writing original draft and review, editing, and visualization. $\mathrm{AN}$ : writing original draft and review, editing, and visualization. $\mathrm{C}-\mathrm{CH}$ : supervision, writing review, and editing. $\mathrm{LH}$ : funding acquisition, project administration, supervision, writing review, and editing.

\section{ACKNOWLEDGMENTS}

We gratefully acknowledge the funding from EPSRC (EP/ R020744/1 and EP/R000441/1). Additionally, the authors would like to acknowledge Callum Shields for the artistic contribution to create Figure 1.

\section{SUPPLEMENTARY MATERIAL}

The Supplementary Material for this article can be found online at: https://www.frontiersin.org/articles/10.3389/fenrg.2020.602918/ full\#supplementary-material.

Alnashef, I. M., Leonard, M. L., Kittle, M. C., Matthews, M. A., and Weidner, J. W. (2001). Electrochemical generation of superoxide in room-temperature ionic liquids. ECS Solid State Lett. 4, D16-D18. doi:10.1149/1.1406997

Aurbach, D., Skaletsky, R., and Gofer, Y. (1991). The electrochemical behavior of calcium electrodes in a few organic electrolytes. J. Electrochem. Soc. 138, 3536. doi:10.1149/1.2085455

Biria, S., Pathreeker, S., Li, H., and Hosein, I. D. (2019). Plating and stripping of calcium in an alkyl carbonate electrolyte at room temperature. ACS Appl. Energy Mater. 2, 7738-7743. doi:10.1021/acsaem.9b01670

Biria, S., Pathreeker, S., Genier, F. S., Li, H., and Hosein, I. D. (2020). Plating and stripping calcium at room temperature in an ionic-liquid electrolyte. ACS Appl. Energy Mater. 3, 2310-2314. doi:10.1021/acsaem.9b02529

Bozorgchenani, M., Fischer, P., Schnaidt, J., Diemant, T., Schwarz, R. M., Marinaro, M., et al. (2018). Electrocatalytic oxygen reduction and oxygen evolution in Mgfree and $\mathrm{Mg}$-containing ionic liquid 1-butyl-1-methylpyrrolidinium bis (trifluoromethanesulfonyl) imide. ChemElectroChem. 5, 2600-2611. doi:10. 1002/celc.201800508 
Brenner, A., and Sligh, J. (1971). Electrodeposition of magnesium and beryllium from organic baths. Trans. Inst. Met. Finish. 49, 71-78. doi:10.1080/00202967.1971.11870170

Brenner, A. (1971). Note on the electrodeposition of magnesium from an organic solution of a magnesium-boron complex. J. Electrochem. Soc. 118, 99. doi:10.1149/1.2407964

Canepa, P., Jayaraman, S., Cheng, L., Rajput, N. N., Richards, W. D., Gautam, G. S., et al. (2015). Elucidating the structure of the magnesium aluminum chloride complex electrolyte for magnesium-ion batteries. Energy Environ. Sci. 8, 3718-3730. doi:10.1039/c5ee02340h

Carbone, L., Moro, P. T., Gobet, M., Munoz, S., Devany, M., Greenbaum, S. G., et al. (2018). Enhanced lithium oxygen battery using a glyme electrolyte and carbon nanotubes. ACS Appl. Mater. Interfaces. 10, 16367-16375. doi:10.1021/acsami. $7 \mathrm{~b} 19544$

Carter, T. J., Mohtadi, R., Arthur, T. S., Mizuno, F., Zhang, R., Shirai, S., et al. (2014). Boron clusters as highly stable magnesium-battery electrolytes. Angew Chem. Int. Ed. Engl. 53, 3173-3177. doi:10.1002/anie.201310317

Chang, Z., Yang, Y., Wang, X., Li, M., Fu, Z., Wu, Y., et al. (2015). Hybrid system for rechargeable magnesium battery with high energy density. Sci. Rep. 5, 11931-11938. doi:10.1038/srep11931

Chen, Y., Freunberger, S. A., Peng, Z., Fontaine, O., and Bruce, P. G. (2013). Charging a Li-O $\mathrm{O}_{2}$ battery using a redox mediator. Nat. Chem. 5, 489. doi:10.1038/nchem.1646

Chen, P., Zhang, K., Tang, D., Liu, W., Meng, F., Huang, Q., et al. (2020). Recent progress in electrolytes for $\mathrm{Zn}$-air batteries. Front. Chem. 8. doi:10.3389/fchem. 2020.00372

Cheng, G., Xu, Q., Zhang, M., Ding, F., Liu, X., and Jiao, L. (2013). Electrochemical reversibility of magnesium deposition-dissolution on aluminum substrates in Grignard reagent/THF solutions. Chin. Sci. Bull. 58, 3385-3389. doi:10.1007/s11434-013-6008-7

Chusid, O., Gofer, Y., Gizbar, H., Vestfrid, Y., Levi, E., Aurbach, D., et al. (2003). Solid-state rechargeable magnesium batteries. Adv. Mater. 15, 627-630. doi:10. 1002/adma.200304415

Connor, J. H., Reid, W. E., Jr, and Wood, G. B. (1957). Electrodeposition of metals from organic solutions: V. Electrodeposition of magnesium and magnesium alloys. J. Electrochem. Soc. 104, 38. doi:10.1149/1.2428492

Das, S., Højberg, J., Knudsen, K. B., Younesi, R., Johansson, P., Norby, P., et al. (2015). Instability of ionic liquid-based electrolytes in $\mathrm{Li}_{-} \mathrm{O}_{2}$ batteries. J. Phys. Chem. C. 119, 18084-18090. doi:10.1021/acs.jpcc.5b04950

De Giorgio, F., Soavi, F., and Mastragostino, M. (2011). Effect of lithium ions on oxygen reduction in ionic liquid-based electrolytes. Electrochem. Commun. 13, 1090-1093. doi:10.1016/j.elecom.2011.07.004

Deivanayagam, R., Cheng, M., Wang, M., Vasudevan, V., Foroozan, T., Medhekar, N. V., et al. (2019). Composite polymer electrolyte for highly cyclable roomtemperature solid-state magnesium batteries. ACS Appl. Energy Mater. 2, 7980-7990. doi:10.1021/acsaem.9b01455

Doe, R. E., Han, R., Hwang, J., Gmitter, A. J., Shterenberg, I., Yoo, H. D., et al. (2014). Novel, electrolyte solutions comprising fully inorganic salts with high anodic stability for rechargeable magnesium batteries. Chem. Commun. 50, 243-245. doi:10.1039/C3CC47896C

Dong, Q., Yao, X., Luo, J., Zhang, X., Hwang, H., and Wang, D. (2016). Enabling rechargeable non-aqueous Mg-O. Chem. Commun. 52, 13753-13756. doi:10. 1039/C6CC07818D

Dongmo, S., Zaubitzer, S., Schüler, P., Krieck, S., Jörissen, L., Wohlfahrt-Mehrens, M., et al. (2020). Stripping and plating a magnesium metal anode in bromide-based nonnucleophilic electrolytes. ChemSusChem. 13, 3530-3538. doi:10.1002/cssc.202000249

Du, A., Zhang, H., Zhang, Z., Zhao, J., Cui, Z., Zhao, Y., et al. (2019). A crosslinked polytetrahydrofuran-borate-based polymer electrolyte enabling wide-workingtemperature-range rechargeable magnesium batteries. Adv. Mater. 31, 1805930. doi:10.1002/adma.201805930

Fan, H., Zhao, Y., Xiao, J., Zhang, J., Wang, M., and Zhang, Y. (2020). A nonnucleophilic gel polymer magnesium electrolyte compatible with sulfur cathode. Nano Res., 1-6. doi:10.1007/s12274-020-2923-5

Fu, J., Liang, R., Liu, G., Yu, A., Bai, Z., Yang, L., et al. (2019). Recent progress in electrically rechargeable zinc-air batteries. Adv. Mater. 31, 1805230. doi:10. 1002/adma.201805230

Gao, X., Mariani, A., Jeong, S., Liu, X., Dou, X., Ding, M., et al. (2019). Prototype rechargeable magnesium batteries using ionic liquid electrolytes. J. Power Sources. 423, 52-59. doi:10.1016/j.jpowsour.2019.03.049

Gelman, D., Shvartsev, B., and Ein-Eli, Y. (2019). "Challenges and prospect of non-aqueous non-alkali (NANA) metal-air batteries," in Electrochemical energy storage: next generation battery concepts. Editor R.-A. Eichel (Cham, Switzerland: Springer International Publishing), 127-168.

Gilmore, P., and Sundaresan, V. B. (2019). A functionally graded cathode architecture for extending the cycle-life of potassium-oxygen batteries. Batteries Supercaps. 2, 678-687. doi:10.1002/batt.201900025

Giridhar, P., El Abedin, S. Z., and Endres, F. (2012). Electrodeposition of aluminium from 1-butyl-1-methylpyrrolidinium chloride/AlCl3 and mixtures with 1-ethyl-3-methylimidazolium chloride/AlCl3. Electrochim. Acta. 70, 210-214. doi:10.1016/j.electacta.2012.03.056

Goossens, K., Rakers, L., Heinrich, B., Ahumada, G., Ichikawa, T., Donnio, B., et al. (2019). Anisotropic, organic ionic plastic crystal mesophases from persubstituted imidazolium pentacyanocyclopentadienide salts. Chem. Mater. 31, 9593-9603. doi:10.1021/acs.chemmater.9b02338

Grande, L., Von Zamory, J., Koch, S. L., Kalhoff, J., Paillard, E., and Passerini, S. (2015). Homogeneous lithium electrodeposition with pyrrolidinium-based ionic liquid electrolytes. ACS Appl. Mater. Interfaces. 7, 5950-5958. doi:10.1021/acsami.5b00209

Gregory, T. D., Hoffman, R. J., and Winterton, R. C. (1990). Nonaqueous electrochemistry of magnesium: applications to energy storage. J. Electrochem. Soc. 137, 775. doi:10.1149/1.2086553

Guo, Y., Yang, J., Nuli, Y., and Wang, J. (2010). Study of electronic effect of Grignard reagents on their electrochemical behavior. Electrochem. Commun. 12, 1671-1673. doi:10.1016/j.elecom.2010.08.015

Guo, Y.-S., Zhang, F., Yang, J., Wang, F.-F., Nuli, Y., and Hirano, S.-I. (2012). Boron-based electrolyte solutions with wide electrochemical windows for rechargeable magnesium batteries. Energy Environ. Sci. 5, 9100-9106. doi:10. 1039/C2EE22509C

Ha, J. H., Adams, B., Cho, J.-H., Duffort, V., Kim, J. H., Chung, K. Y., et al. (2016). A conditioning-free magnesium chloride complex electrolyte for rechargeable magnesium batteries. J. Mater. Chem. 4, 7160-7164. doi:10.1039/C6TA01684G

Ha, T. A., Pozo-Gonzalo, C., Nairn, K., Macfarlane, D. R., Forsyth, M., and Howlett, P. C. (2020). An investigation of commercial carbon air cathode structure in ionic liquid based sodium oxygen batteries. Sci. Rep. 10, 1-10. doi:10.1038/s41598-020-63473-y

Haas, I., and Gedanken, A. (2008). Synthesis of metallic magnesium nanoparticles by sonoelectrochemistry. Chem. Commun., 1795-1797. doi:10.1039/B717670H

Han, S.-D., Rajput, N. N., Qu, X., Pan, B., He, M., Ferrandon, M. S., et al. (2016). Origin of electrochemical, structural, and transport properties in nonaqueous zinc electrolytes. ACS Appl. Mater. Interfaces. 8, 3021-3031. doi:10.1021/ acsami.5b10024

Han, S., Cai, C., Yang, F., Zhu, Y., Sun, Q., Zhu, Y. G., et al. (2020). Interrogation of the reaction mechanism in a $\mathrm{Na}-\mathrm{O} 2$ battery using in situ transmission electron microscopy. ACS Nano. 14, 3669-3677. doi:10.1021/acsnano.0c00283

Hardwick, L. J., and De León, C. P. (2018). Rechargeable multi-valent metal-air batteries. Johnson Matthey Technol. Rev. 62, 134-149. doi:10.1595/ 205651318X696729

Hartmann, P., Bender, C. L., Vračar, M., Dürr, A. K., Garsuch, A., Janek, J., et al. (2013). A rechargeable room-temperature sodium superoxide $\left(\mathrm{NaO}_{2}\right)$ battery. Nat. Mater. 12, 228-232. doi:10.1038/NMAT3486

Haynes, W. M. (2014). CRC handbook of chemistry and physics. Boca Raton, FL: CRC Press.

He, S., Nielson, K. V., Luo, J., and Liu, T. L. (2017). Recent advances on $\mathrm{MgCl} 2$ based electrolytes for rechargeable Mg batteries. Energy Stor. Mater. 8, 184-188. doi:10.1016/j.ensm.2016.12.001

Hegemann, P., Hegemann, M., Zan, L., and Baltruschat, H. (2019). Stability of tetraglyme for reversible magnesium deposition from a magnesium aluminum chloride complex. J. Electrochem. Soc. 166, A245. doi:10.1149/2.0871902jes

Higashi, S., Miwa, K., Aoki, M., and Takechi, K. (2014). A novel inorganic solid state ion conductor for rechargeable $\mathrm{Mg}$ batteries. Chem. Commun. 50, 1320-1322. doi:10.1039/C3CC47097K

Hu, K., Qin, L., Zhang, S., Zheng, J., Sun, J., Ito, Y., et al. (2020). Building a reactive armor using S-doped graphene for protecting potassium metal anodes from oxygen crossover in $\mathrm{K}-\mathrm{O}_{2}$ batteries. ACS Energy Lett. doi:10.1021/acsenergylett.0c00715

Hwang, H. J., Chi, W. S., Kwon, O., Lee, J. G., Kim, J. H., and Shul, Y.-G. (2016). Selective ion transporting polymerized ionic liquid membrane separator for enhancing cycle stability and durability in secondary zinc-air battery systems. ACS Appl. Mater. Interfaces. 8, 26298-26308. doi:10.1021/acsami. 6b07841 
Jäckle, M., Helmbrecht, K., Smits, M., Stottmeister, D., and Gro $\beta$, A. (2018). Selfdiffusion barriers: possible descriptors for dendrite growth in batteries? Energy Environ. Sci. 11, 3400-3407. doi:10.1039/C8EE01448E

Jaschin, P. W., Gao, Y., Li, Y., and Bo, S.-H. (2020). A materials perspective on magnesium-ion-based solid-state electrolytes. J. Mater. Chem. 8, 2875-2897. doi:10.1039/C9TA11729F

Jin, L., Howlett, P. C., Pringle, J. M., Janikowski, J., Armand, M., Macfarlane, D. R., et al. (2014). An organic ionic plastic crystal electrolyte for rate capability and stability of ambient temperature lithium batteries. Energy Environ. Sci. 7, 3352-3361. doi:10.1039/C4EE01085J

Johnson, L., Li, C., Liu, Z., Chen, Y., Freunberger, S. A., Ashok, P. C., et al. (2014). The role of $\mathrm{LiO}_{2}$ solubility in $\mathrm{O}_{2}$ reduction in aprotic solvents and its consequences for Li- $\mathrm{O}_{2}$ batteries. Nat. Chem. 6, 1091. doi:10.1038/nchem.2101

Jusys, Z., Schnaidt, J., and Behm, R. J. (2019). $\mathrm{O}_{2}$ reduction on a Au film electrode in an ionic liquid in the absence and presence of $\mathrm{Mg}^{2+}$ ions: product formation and adlayer dynamics. J. Chem. Phys. 150, 041724. doi:10.1063/1.5051982

Kakibe, T., Yoshimoto, N., Egashira, M., and Morita, M. (2010). Optimization of cation structure of imidazolium-based ionic liquids as ionic solvents for rechargeable magnesium batteries. Electrochem. Commun. 12, 1630-1633. doi:10.1016/j.elecom.2010.09.012

Kakibe, T., Hishii, J.-Y., Yoshimoto, N., Egashira, M., and Morita, M. (2012). Binary ionic liquid electrolytes containing organo-magnesium complex for rechargeable magnesium batteries. J. Power Sources. 203, 195-200. doi:10.1016/ j.jpowsour.2011.10.127

Katayama, Y., Sekiguchi, K., Yamagata, M., and Miura, T. (2005). Electrochemical behavior of oxygen/superoxide ion couple in 1-butyl-1-methylpyrrolidinium bis (trifluoromethylsulfonyl) imide room-temperature molten salt. J. Electrochem. Soc. 152, E247-E250. doi:10.1149/1.1946530

Khan, A., and Zhao, C. (2014). Enhanced performance in mixture DMSO/ionic liquid electrolytes: toward rechargeable $\mathrm{Li}-\mathrm{O}_{2}$ batteries. Electrochem. Commun. 49, 1-4. doi:10.1016/j.elecom.2014.09.014

Kim, Y.-S., Cho, Y.-G., Odkhuu, D., Park, N., and Song, H.-K. (2013). A physical organogel electrolyte: characterized by in situ thermo-irreversible gelation and single-ion-predominent conduction. Sci. Rep. 3, 1-6. doi:10.1038/srep01917

Kim, M.-J., Kang, H.-J., Im, W. B., and Jun, Y.-S. (2020). Rechargeable intermetallic calcium-lithium- $\mathrm{O}_{2}$ batteries. ChemSusChem. 13, 574-581. doi:10.1002/cssc. 201902925

Kumar, G. G., and Munichandraiah, N. (1999). Reversibility of Mg/Mg2+ couple in a gel polymer electrolyte. Electrochim. Acta. 44, 2663-2666. doi:10.1016/S00134686(98)00388-0

Kundu, D., Black, R., Adams, B., and Nazar, L. F. (2015). A highly active low voltage redox mediator for enhanced rechargeability of lithium-oxygen batteries. ACS Cent. Sci. 1, 510-515. doi:10.1021/acscentsci.5b00267

Lair, V., Sirieix-Plenet, J., Gaillon, L., Rizzi, C., and Ringuedé, A. (2010). Mixtures of room temperature ionic liquid/ethanol solutions as electrolytic media for cerium oxide thin layer electrodeposition. Electrochim. Acta. 56, 784-789. doi:10.1016/j.electacta.2010.09.102

Law, Y. T., Schnaidt, J., Brimaud, S., and Behm, R. J. (2016). Oxygen reduction and evolution in an ionic liquid ([BMP][TFSA]) based electrolyte: a model study of the cathode reactions in Mg-air batteries. J. Power Sources. 333, 173-183. doi:10. 1016/j.jpowsour.2016.09.025

Lee, B., Cho, J.-H., Seo, H. R., Na, S. B., Kim, J. H., Cho, B. W., et al. (2018). Strategic combination of Grignard reagents and allyl-functionalized ionic liquids as an advanced electrolyte for rechargeable magnesium batteries. J. Mater. Chem. 6, 3126-3133. doi:10.1039/C7TA09330F

Leisegang, T., Meutzner, F., Zschornak, M., Münchgesang, W., Schmid, R., Nestler, T., et al. (2019). The aluminum-ion battery: a sustainable and seminal concept?. Front. Chem. 7, 268. doi:10.3389/fchem.2019.00268

Leng, L., Zeng, X., Chen, P., Shu, T., Song, H., Fu, Z., et al. (2015). A novel stabilityenhanced lithium-oxygen battery with cellulose-based composite polymer gel as the electrolyte. Electrochim. Acta. 176, 1108-1115. doi:10.1016/j.electacta. 2015.07.111

Li, C. S., Sun, Y., Gebert, F., and Chou, S. L. (2017). Current progress on rechargeable magnesium-air battery. Adv. Energy Mater. 7, 1700869. doi:10. 1002/aenm.201700869

Li, Z., Fuhr, O., Fichtner, M., and Zhao-Karger, Z. (2019). Towards stable and efficient electrolytes for room-temperature rechargeable calcium batteries. Energy Environ. Sci. 12, 3496-3501. doi:10.1039/C9EE01699F
Li, C., Wei, J.-S., Qiu, K., and Wang, Y.-G. (2020a). Li-air battery with a superhydrophobic Li-protective layer. ACS Appl. Mater. Interfaces. doi:10.1021/ acsami.0c05494

Li, X., Xing, Y., Xu, J., Deng, Q., and Shao, L.-H. (2020b). Uniform yolk-shell structured $\mathrm{Si}-\mathrm{C}$ nanoparticles as a high performance anode material for the Liion battery. Chem. Commun. doi:10.1039/C9CC07997A

Liang, F., and Hayashi, K. (2015). A high-energy-density mixed-aprotic-aqueous sodium-air cell with a ceramic separator and a porous carbon electrode. J. Electrochem. Soc. 162, A1215. doi:10.1149/2.0421507jes

Liebenow, C., Yang, Z., and Lobitz, P. (2000). The electrodeposition of magnesium using solutions of organomagnesium halides, amidomagnesium halides and magnesium organoborates. Electrochem. Commun. 2, 641-645. doi:10.1016/ S1388-2481(00)00094-1

Liebenow, C. (1997). Reversibility of electrochemical magnesium deposition from Grignard solutions. J. Appl. Electrochem. 27, 221-225. doi:10.1023/A:1018464210084

Liu, T., Shao, Y., Li, G., Gu, M., Hu, J., Xu, S., et al. (2014). A facile approach using $\mathrm{MgCl}_{2}$ to formulate high performance $\mathrm{Mg}^{2+}$ electrolytes for rechargeable $\mathrm{Mg}$ batteries. J. Mater. Chem. 2, 3430-3438. doi:10.1039/C3TA14825D

Liu, Z., Cui, T., Pulletikurthi, G., Lahiri, A., Carstens, T., Olschewski, M., et al. (2016). Dendrite-free nanocrystalline zinc electrodeposition from an ionic liquid containing nickel triflate for rechargeable $\mathrm{Zn}$-based batteries. Angew. Chem. Int. Ed. 55, 2889-2893. doi:10.1002/anie.201509364

Liu, J., Bao, Z., Cui, Y., Dufek, E. J., Goodenough, J. B., Khalifah, P., et al. (2019). Pathways for practical high-energy long-cycling lithium metal batteries. Nat. Energy. 4, 180-186. doi:10.1038/s41560-019-0338-x

Lu, Y.-T., Chien, Y.-J., Liu, C.-F., You, T.-H., and Hu, C.-C. (2017). Active siteengineered bifunctional electrocatalysts of ternary spinel oxides, $\mathrm{M}_{0.1} \mathrm{Ni}_{0.9} \mathrm{Co}_{2} \mathrm{O}_{4}$ (M: $\mathrm{Mn}, \mathrm{Fe}, \mathrm{Cu}, \mathrm{Zn}$ ) for the air electrode of rechargeable zinc-air batteries. J. Mater. Chem. 5, 21016-21026. doi:10.1039/C7TA06302D

Luo, J., Bi, Y., Zhang, L., Zhang, X., and Liu, T. L. (2019a). A stable, non-corrosive perfluorinated pinacolatoborate $\mathrm{Mg}$ electrolyte for rechargeable $\mathrm{Mg}$ batteries. Angew. Chem. Int. Ed. 58, 6967-6971. doi:10.1002/anie.201902009

Luo, Z., Li, Y., Liu, Z., Pan, L., Guan, W., Liu, P., et al. (2019b). Prolonging the cycle life of a lithium-air battery by alleviating electrolyte degradation with a ceramic-carbon composite cathode. ChemSusChem. 12, 4962-4967. doi:10. $1002 /$ cssc. 201901629

Ma, Z., Forsyth, M., Macfarlane, D. R., and Kar, M. (2019). Ionic liquid/tetraglyme hybrid $\mathrm{Mg}[\mathrm{TFSI}]_{2}$ electrolytes for rechargeable Mg batteries. Green Energy Environ. 4, 146-153. doi:10.1016/j.gee.2018.10.003

Macfarlane, D. R., Huang, J., and Forsyth, M. (1999). Lithium-doped plastic crystal electrolytes exhibiting fast ion conduction for secondary batteries. Nature. 402, 792-794. doi:10.1038/45514

Mizrahi, O., Amir, N., Pollak, E., Chusid, O., Marks, V., Gottlieb, H., et al. (2008). Electrolyte solutions with a wide electrochemical window for rechargeable magnesium batteries. J. Electrochem. Soc. 155, A103-A109. doi:10.1149/1. 2806175

Monaco, S., Soavi, F., and Mastragostino, M. (2013). Role of oxygen mass transport in rechargeable $\mathrm{Li} / \mathrm{O}_{2}$ batteries operating with ionic liquids. J. Phys. Chem. Lett. 4, 1379-1382. doi:10.1021/jz4006256

Muldoon, J., Bucur, C. B., Oliver, A. G., Sugimoto, T., Matsui, M., Kim, H. S., et al. (2012). Electrolyte roadblocks to a magnesium rechargeable battery. Energy Environ. Sci. 5, 5941-5950. doi:10.1039/C2EE03029B

Muldoon, J., Bucur, C. B., and Gregory, T. (2014). Quest for nonaqueous multivalent secondary batteries: magnesium and beyond. Chem. Rev. 114, 11683-11720. doi:10.1021/cr500049y

Narayanan, N. V., Raj, B. A., and Sampath, S. (2009). Magnesium ion conducting, room temperature molten electrolytes. Electrochem. Commun. 11, 2027-2031. doi:10.1016/j.elecom.2009.08.045

Neale, A. R., Li, P., Jacquemin, J., Goodrich, P., Ball, S. C., Compton, R. G., et al. (2016). Effect of cation structure on the oxygen solubility and diffusivity in a range of bis $\{$ (trifluoromethyl)sulfonyl\}imide anion based ionic liquids for lithium-air battery electrolytes. Phys. Chem. Chem. Phys. 18, 11251-11262. doi:10.1039/C5CP07160G

Neale, A. R., Goodrich, P., Hughes, T.-L., Hardacre, C., Ball, S. C., and Jacquemin, J. (2017). Physical and electrochemical investigations into blended electrolytes containing a glyme solvent and two bis \{(trifluoromethyl) sulfonyl\} imide-based ionic liquids. J. Electrochem. Soc. 164, H5124. doi:10.1149/2.0141708jes 
Ng, B., Peng, X., Faegh, E., and Mustain, W. E. (2020). Using nanoconfinement to inhibit the degradation pathways of conversion-metal oxide anodes for highly stable fast-charging Li-ion batteries. J. Mater. Chem. 8, 2712-2727. doi:10.1039/ C9TA11708C

Ogasawara, T., Débart, A., Holzapfel, M., Novák, P., and Bruce, P. G. (2006). Rechargeable $\mathrm{Li}_{2} \mathrm{O}_{2}$ electrode for lithium batteries. J. Am. Chem. Soc. 128, 1390-1393. doi:10.1021/ja056811q

Ortiz-Vitoriano, N., Batcho, T. P., Kwabi, D. G., Han, B., Pour, N., Yao, K. P. C., et al. (2015). Rate-dependent nucleation and growth of $\mathrm{NaO}_{2}$ in $\mathrm{Na}-\mathrm{O}_{2}$ batteries. J. Phys. Chem. Lett. 6, 2636-2643. doi:10.1021/acs. jpclett.5b00919

Overcash, D. M., and Mathers, F. (1933). The electrodeposition of magnesium. Trans. Electrochem. Soc. 64, 305. doi:10.1149/1.3504531

Pandey, G., and Hashmi, S. (2009). Experimental investigations of an ionic-liquidbased, magnesium ion conducting, polymer gel electrolyte. J. Power Sources. 187, 627-634. doi:10.1016/j.jpowsour.2008.10.112

Ponrouch, A., Frontera, C., Bardé, F., and Palacín, M. R. (2016). Towards a calcium-based rechargeable battery. Nat. Mater. 15, 169-172. doi:10.1038/ nmat4462

Ponrouch, A., Bitenc, J., Dominko, R., Lindahl, N., Johansson, P., and Palacin, M. R. (2019). Multivalent rechargeable batteries. Energy Stor. Mater. doi:10.1016/j. ensm.2019.04.012

Pour, N., Gofer, Y., Major, D. T., and Aurbach, D. (2011). Structural analysis of electrolyte solutions for rechargeable $\mathrm{Mg}$ batteries by stereoscopic means and DFT calculations. J. Am. Chem. Soc. 133, 6270-6278. doi:10.1021/ja1098512

Pringle, J. M., Howlett, P. C., Macfarlane, D. R., and Forsyth, M. (2010). Organic ionic plastic crystals: recent advances. J. Mater. Chem. 20, 2056-2062. doi:10. 1039/B920406G

Pujare, N. U. (1988). A calcium oxygen secondary battery. J. Electrochem. Soc. 135, 260. doi:10.1149/1.2095574

Reinsberg, P., Bondue, C., and Baltruschat, H. (2016a). Mechanistic investigation of the oxygen reduction in magnesium ion-containing dimethyl sulfoxide. Electrochim. Acta. 200, 214-221. doi:10.1016/j.electacta.2016.03.157

Reinsberg, P., Bondue, C. J., and Baltruschat, H. (2016b). Calcium-oxygen batteries as a promising alternative to sodium-oxygen batteries. J. Phys. Chem. C. 120, 22179-22185. doi:10.1021/acs.jpcc.6b06674

Reinsberg, P., Abd-El-Latif, A.-E.-a. A., and Baltruschat, H. (2018). Investigation of the complex influence of divalent cations on the oxygen reduction reaction in aprotic solvents. Electrochim. Acta. 273, 424-431. doi:10.1016/j.electacta.2018.03.123

Ren, X., and $\mathrm{Wu}, \mathrm{Y}$. (2013). A low-overpotential potassium-oxygen battery based on potassium superoxide. J. Am. Chem. Soc. 135, 2923-2926. doi:10.1021/ja312059q

Sarangika, H., Dissanayake, M., Senadeera, G., Rathnayake, R., and Pitawala, H. (2017). Polyethylene oxide and ionic liquid-based solid polymer electrolyte for rechargeable magnesium batteries. Ionics. 23, 2829-2835. doi:10.1007/s11581016-1870-3

Sawyer, D. T., Calderwood, T. S., Yamaguchi, K., and Angelis, C. T. (1983). Synthesis and characterization of tetramethylammonium superoxide. Inorg. Chem. 22, 2577-2583. doi:10.1021/ic00160a022

See, K. A., Liu, Y.-M., Ha, Y., Barile, C. J., and Gewirth, A. A. (2017). Effect of concentration on the electrochemistry and speciation of the magnesium aluminum chloride complex electrolyte solution. ACS Appl. Mater. Interfaces. 9, 35729-35739. doi:10.1021/acsami.7b08088

Shao, Y., Rajput, N. N., Hu, J., Hu, M., Liu, T., Wei, Z., et al. (2015). Nanocomposite polymer electrolyte for rechargeable magnesium batteries. Nanomater. Energy. 12, 750-759. doi:10.1016/j.nanoen.2014.12.028

Sheng, C., Yu, F., Wu, Y., Peng, Z., and Chen, Y. (2018). Disproportionation of sodium superoxide in metal-air batteries. Angew. Chem. Int. Ed. 57, 9906-9910. doi:10.1002/anie.201804726

Shiga, T., Hase, Y., Kato, Y., Inoue, M., and Takechi, K. (2013). A rechargeable nonaqueous $\mathrm{Mg}-\mathrm{O}_{2}$ battery. Chem. Commun. 49, 9152-9154. doi:10.1039/ C3CC43477J

Shiga, T., Kato, Y., and Hase, Y. (2017). Coupling of nitroxyl radical as an electrochemical charging catalyst and ionic liquid for calcium plating/ stripping toward a rechargeable calcium-oxygen battery. J. Mater. Chem. 5, 13212-13219. doi:10.1039/C7TA03422A

Shterenberg, I., Salama, M., Gofer, Y., Levi, E., and Aurbach, D. (2014). The challenge of developing rechargeable magnesium batteries. MRS Bull. 39, 453-460. doi:10.1557/mrs.2014.61
Shyamsunder, A., Blanc, L. E., Assoud, A., and Nazar, L. F. (2019). Reversible calcium plating and stripping at room temperature using a borate salt. ACS Energy Lett. 4, 2271-2276. doi:10.1021/acsenergylett.9b01550

Smith, J. G., Naruse, J., Hiramatsu, H., and Siegel, D. J. (2016). Theoretical limiting potentials in $\mathrm{Mg} / \mathrm{O}_{2}$ batteries. Chem. Mater. 28, 1390-1401. doi:10.1021/acs. chemmater.5b04501

Staniewicz, R. J. (1980). A study of the calcium-thionyl chloride electrochemical system. J. Electrochem. Soc. 127, 782. doi:10.1149/1.2129758

Ta, K., Zhang, R., Shin, M., Rooney, R. T., Neumann, E. K., and Gewirth, A. A. (2019). Understanding $\mathrm{Ca}$ electrodeposition and speciation processes in nonaqueous electrolytes for next-generation Ca-ion batteries. ACS Appl. Mater. Interfaces. 11, 21536-21542. doi:10.1021/acsami.9b04926

Tchitchekova, D., Monti, D., Johansson, P., Bardé, F., Randon-Vitanova, A., Palacín, M., et al. (2017). On the reliability of half-cell tests for monovalent $\left(\mathrm{Li}^{+}, \mathrm{Na}^{+}\right)$and divalent $\left(\mathrm{Mg}^{2+}, \mathrm{Ca}^{2+}\right)$ cation based batteries. J. Electrochem. Soc. 164, A1384-A1392. doi:10.1149/2.0411707jes

Trahan, M. J., Mukerjee, S., Plichta, E. J., Hendrickson, M. A., and Abraham, K. (2012). Studies of Li-air cells utilizing dimethyl sulfoxide-based electrolyte. J. Electrochem. Soc. 160, A259. doi:10.1149/2.048302jes

Vardar, G., Nelson, E. G., Smith, J. G., Naruse, J., Hiramatsu, H., Bartlett, B. M., et al. (2015). Identifying the discharge product and reaction pathway for a secondary $\mathrm{Mg} / \mathrm{O}_{2}$ battery. Chem. Mater. 27, 7564-7568. doi:10.1021/acs. chemmater.5b03608

Viestfrid, Y., Levi, M., Gofer, Y., and Aurbach, D. (2005). Microelectrode studies of reversible $\mathrm{Mg}$ deposition in THF solutions containing complexes of alkylaluminum chlorides and dialkylmagnesium. J. Electroanal. Chem. 576, 183-195. doi:10.1016/j.jelechem.2004.09.034

Wang, D., Gao, X., Chen, Y., Jin, L., Kuss, C., and Bruce, P. G. (2018a). Plating and stripping calcium in an organic electrolyte. Nat. Mater. 17, 16-20. doi:10.1038/nmat5036

Wang, W., Lai, N. C., Liang, Z., Wang, Y., and Lu, Y. C. (2018b). Superoxide stabilization and a universal $\mathrm{KO}_{2}$ growth mechanism in potassium-oxygen batteries. Angew. Chem. Int. Ed. 57, 5042-5046. doi:10.1002/anie.201801344

Wang, H., Feng, X., Chen, Y., Liu, Y.-S., Han, K. S., Zhou, M., et al. (2019a). Reversible electrochemical interface of $\mathrm{Mg}$ metal and conventional electrolyte enabled by intermediate adsorption. ACS Energy Lett. 5, 200-206. doi:10.1021/ acsenergylett.9b02211

Wang, S., Cai, W., Sun, Z., Huang, F., Jie, Y., Liu, Y., et al. (2019b). Stable cycling of Na metal anodes in a carbonate electrolyte. Chem. Commun. 55, 14375-14378. doi:10.1039/C9CC07419H

Watkins, T., Kumar, A., and Buttry, D. A. (2016). Designer ionic liquids for reversible electrochemical deposition/dissolution of magnesium. J. Am. Chem. Soc. 138, 641-650. doi:10.1021/jacs.5b11031

Xiao, N., Gourdin, G., and Wu, Y. (2018). Simultaneous stabilization of potassium metal and superoxide in $\mathrm{K}-\mathrm{O}_{2}$ batteries on the basis of electrolyte reactivity. Angew. Chem. Int. Ed. 57, 10864-10867. doi:10.1002/anie.201804115

Yang, W., Salim, J., Ma, C., Ma, Z., Sun, C., Li, J., et al. (2013). Flowerlike $\mathrm{Co}_{3} \mathrm{O}_{4}$ microspheres loaded with copper nanoparticle as an efficient bifunctional catalyst for lithium-air batteries. Electrochem. Commun. 28, 13-16. doi:10. 1016/j.elecom.2012.12.007

Yao, Z., Hegde, V. I., Aspuru-Guzik, A., and Wolverton, C. (2019). Discovery of calcium-metal alloy anodes for reversible Ca-ion batteries. Adv. Energy Mater. 9, 1802994. doi:10.1002/aenm.201802994

Yi, J., Liu, X., Guo, S., Zhu, K., Xue, H., and Zhou, H. (2015). Novel stable gel polymer electrolyte: toward a high safety and long life Li-air battery. ACS Appl. Mater. Interfaces. 7, 23798-23804. doi:10.1021/acsami.5b08462

Yin, W.-W., Yue, J.-L., Cao, M.-H., Liu, W., Ding, J.-J., Ding, F., et al. (2015). Dual catalytic behavior of a soluble ferrocene as an electrocatalyst and in the electrochemistry for Na-air batteries. J. Mater. Chem. 3, 19027-19032. doi:10.1039/C5TA04647E

Yu, W., Lau, K. C., Lei, Y., Liu, R., Qin, L., Yang, W., et al. (2017). Dendrite-free potassium-oxygen battery based on a liquid alloy anode. ACS Appl. Mater. Interfaces. 9, 31871-31878. doi:10.1021/acsami.7b08962

Zhang, J., Zhou, Q., Tang, Y., Zhang, L., and Li, Y. (2019). Zinc-air batteries: are they ready for prime time?. Chem. Sci. 10, 8924-8929. doi:10.1039/c9sc04221k

Zhao, Q. S., Nuli, Y. N., Guo, Y. S., Yang, J., and Wang, J. L. (2011). Reversibility of electrochemical magnesium deposition from tetrahydrofuran solutions containing pyrrolidinyl magnesium halide. Electrochim. Acta. 56, 6530-6535. doi:10.1016/j.electacta.2011.04.114 
Zhao, X., Chen, F., Liu, J., Cheng, M., Su, H., Liu, J., et al. (2020). Enhanced surface binding energy regulates uniform potassium deposition for stable potassium metal anodes. J. Mater. Chem. 8, 5671-5678. doi:10.1039/ C9TA14226F

Zhou, Z.-B., and Matsumoto, H. (2007). Lithium-doped, organic ionic plastic crystal electrolytes exhibiting high ambient-temperature conductivities. Electrochem. Commun. 9, 1017-1022. doi:10.1016/j.elecom.2006.12.012

Zhu, J., Guo, Y., Yang, J., Nuli, Y., Zhang, F., Wang, J., et al. (2014). Halogen-free boron based electrolyte solution for rechargeable magnesium batteries. J. Power Sources 248, 690-694. doi:10.1016/j.jpowsour.2013.09.124
Conflict of Interest: The authors declare that the research was conducted in the absence of any commercial or financial relationships that could be construed as a potential conflict of interest.

Copyright (c) $2021 \mathrm{Lu}$, Neale, Hu and Hardwick. This is an open-access article distributed under the terms of the Creative Commons Attribution License (CC BY). The use, distribution or reproduction in other forums is permitted, provided the original author(s) and the copyright owner(s) are credited and that the original publication in this journal is cited, in accordance with accepted academic practice. No use, distribution or reproduction is permitted which does not comply with these terms. 